\title{
REVIEW
}

\section{Pulmonary aspergillosis: a clinical review}

\author{
M. Kousha, R. Tadi and A.O. Soubani
}

\begin{abstract}
Aspergillus is a mould which may lead to a variety of infectious, allergic diseases depending on the host's immune status or pulmonary structure. Invasive pulmonary aspergillosis occurs primarily in patients with severe immunodeficiency. The significance of this infection has dramatically increased with growing numbers of patients with impaired immune state associated with the management of malignancy, organ transplantation, autoimmune and inflammatory conditions; critically ill patients and those with chronic obstructive pulmonary disease appear to be at an increased risk. The introduction of new noninvasive tests, combined with more effective and better-tolerated antifungal agents, has resulted in lower mortality rates associated with this infection. Chronic necrotising aspergillosis is a locally invasive disease described in patients with chronic lung disease or mild immunodeficiency. Aspergilloma is usually found in patients with previously formed cavities in the lung, whereas allergic bronchopulmonary aspergillosis, a hypersensitivity reaction to Aspergillus antigens, is generally seen in patients with atopy, asthma or cystic fibrosis. This review provides an update on the evolving epidemiology and risk factors of the major manifestations of Aspergillus lung disease and the clinical manifestations that should prompt the clinician to consider these conditions. Current approaches for the diagnosis and management of these syndromes are discussed.
\end{abstract}

KEYWORDS: Aspergillosis, diagnosis, management, pulmonary, risk factors

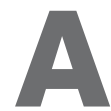
spergillus spp. are widespread in the environment and are commonly isolated from both the outdoor environment (i.e. soil, plant debris) and indoor environment, including hospitals. Pulmonary disease is caused mainly by Aspergillus fumigatus and has a spectrum of clinical syndromes (fig. 1) [1].

Invasive pulmonary aspergillosis (IPA) is a severe disease, and can be found not only in severely immunocompromised patients, but also in critically ill patients and those with chronic obstructive pulmonary disease (COPD). Chronic necrotising aspergillosis (CNA) is locally invasive and is seen mainly in patients with mild immunodeficiency or with a chronic lung disease. Aspergilloma and allergic bronchopulmonary aspergillosis (ABPA) are noninvasive forms of Aspergillus lung disease. Aspergilloma is a fungus ball that develops in a pre-existing cavity within the lung parenchyma, while ABPA is a hypersensitivity manifestation in the lungs that almost always affects patients with asthma or cystic fibrosis [2].

This review systematically describes the main clinical syndromes associated with pulmonary aspergillosis, covering their incidence, risk factors, clinical presentations, radiological features, diagnostic criteria, management options and outcome.

\section{INVASIVE PULMONARY ASPERGILLOSIS}

IPA was first described in 1953 [3]. Due to widespread use of chemotherapy and immunosuppressive agents, its incidence has increased over the past two decades [4,5]. Of all autopsies performed between 1978 and 1992, the rate of invasive mycoses increased from $0.4 \%$ to $3.1 \%$, as documented by GROLL et al. [6]. IPA increased from $17 \%$ to $60 \%$ of all mycoses found on autopsy over the course of the study. The mortality rate of IPA exceeds $50 \%$ in neutropenic patients and reaches $90 \%$ in haematopoietic stem-cell transplantation (HSCT) recipients [7, 8].

\section{Risk factors}

Alveolar macrophages are the first line of defence against inhaled Aspergillus conidia. In the lungs, pathogen recognition receptors, such as Toll-like receptors, dectin-1 and mannose-binding lectin, identify specific fungal wall components and produce cytokines that stimulate neutrophil recruitment, the main defence mechanism against Aspergillus hyphae [9]. The major risk factor for IPA is immunodeficiency (table 1), which
AFFILIATION

Division of Pulmonary Critical Care and Sleep Medicine, Wayne State University School of Medicine, Detroit, MI, USA.

\section{CORRESPONDENCE}

A.O. Soubani

Division of Pulmonary Critical Care and Sleep Medicine

Wayne State University

School of Medicine

Harper University Hospital

3990 John R - 3 Hudson

Detroit

MI 48201

USA

E-mail: asoubani@med.wayne.edu

Received:

Jan 232011

Accepted after revision:

March 102011

PROVENANCE

Submitted article, peer reviewed

Online ISSN 1600-0617 


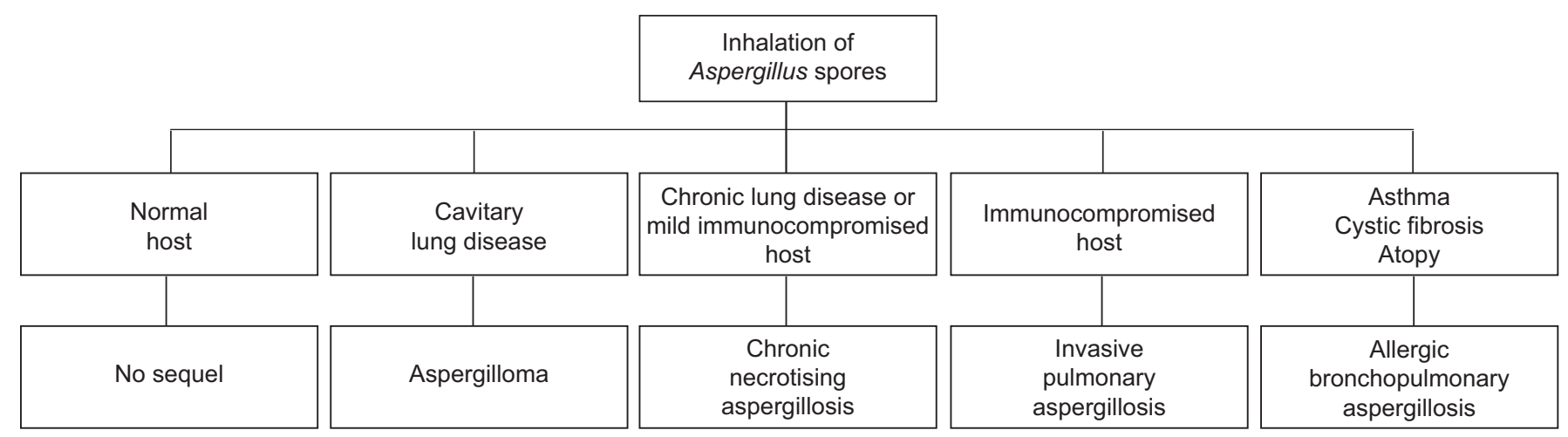

FIGURE 1. The spectrum of pulmonary aspergillosis.

includes neutropenia, HSCT and solid-organ transplantation, prolonged therapy with high-dose corticosteroids, haematological malignancy, cytotoxic therapy, advanced AIDS and chronic granulomatous disease (CGD) [1, 10, 15].

The most important risk factor is neutropenia, especially when there is an absolute neutrophil count of $<500$ cells $\cdot \mathrm{mm}^{-3}$. The risk of IPA correlates strongly with the duration and degree of neutropenia. The risk in neutropenic patients is estimated to increase by $1 \%$ per day for the first 3 weeks and then by $4 \%$ per day thereafter [10]. HSCT and solid-organ transplantation (especially lung transplantation) are also significant risk factors $[11,23]$ Several other factors predispose patients with transplantation to acquire IPA: multiple immune defects including prolonged neutropenia in the pre-engraftment phase of HSCT; the use of multiple anti-rejection or anti-graft versus host disease (GVHD) therapy (such as corticosteroids and cyclosporine); parenteral nutrition; use of multiple antibiotics; and prolonged hospitalisation.

There has been a steady increase in the documented cases of IPA following HSCT, where the risk is much higher following allogeneic rather than autologous HSCT (incidences of 2.3-15\% and $0.5-4 \%$, respectively) $[8,12-14,24]$. In allogeneic HSCT, the highest risk is in patients with severe GVHD (grade III-IV). The timeline of IPA in these patients follows a bimodal distribution, with a peak in the first month following HSCT, which is associated with neutropenia. The second peak is during the treatment of GVHD (median 78-112 days post-transplantation) $[8,13,25]$. Currently, the first peak is less significant because of the routine use of stem cells instead of bone marrow for transplantation, nonmyeloablative regimens, the use of colonystimulating factors during neutropenia and the widespread use of antifungal agents $[13,26]$. The second peak has become more significant, especially with the higher incidence of GVHD associated with unrelated allogeneic transplantation and treatment with intensive immunosuppressive therapy, including corticosteroids, cyclosporine A, anti-TNF agents, and other T-cell depleting strategies [13, 14, 17, 27-29].

In a study by MARR et al. [14], the probability of IPA reached approximately $5 \%$ at 2 months, $9 \%$ at 6 months, $10 \%$ at 1 year and $11.1 \%$ by the third year following allogeneic HSCT. In addition, there is evidence that cytomegalovirus (CMV) infection in these patients increases the risk of IPA $[14,30]$ the hazard ratio for IPA in the setting of CMV disease increases 13.3-fold (95\% CI 4.7-37.7) [8].

Neutrophil dysfunction is another risk factor for IPA and is seen primarily in CGD. IPA is an important cause of mortality in these patients [22].

IPA is relatively uncommon in patients with HIV infection, especially with the routine use of highly active anti-retroviral therapy. The incidence of aspergillosis in a large cohort of patients with HIV infection was 3.5 cases per 1,000 person-yrs [18]. A low CD4 count $\left(<100\right.$ cells $\left.\cdot \mathrm{mm}^{-3}\right)$ is present in almost all cases of AIDS-associated aspergillosis, and half of HIVinfected patients with IPA have coexistent neutropenia or are on corticosteroid therapy. The rest of the cases appear to have no particular risk factors other than advanced AIDS [19-21]. There is increased incidence of tracheobronchial involvement in these patients in addition to the usual clinical picture of IPA $[21,31]$. Since isolation of Aspergillus from respiratory secretions has poor predictive value for invasive IPA in AIDS patients, a histopathological diagnosis is usually required to establish the diagnosis [32]. Response to therapy in this patient group tends to be particularly poor [19-21, 32, 33]. The prognosis of HIV-infected patients with IPA is generally poor, with median survival of 3 months following diagnosis [18].

There are increasing numbers of reports documenting IPA in immunocompetent patients who do not have the classic risk factors. Two at-risk groups stand out: patients with severe COPD and critically ill patients. IPA is an emerging serious infection in patients with COPD. The majority of these patients have advanced COPD and/or are on corticosteroid therapy. Patients with COPD have increased susceptibility to IPA for several reasons, including structural changes in lung architecture, prolonged use of corticosteroid therapy [16], frequent hospitalisation, broad-spectrum antibiotic treatment, invasive procedures, mucosal lesions and impaired mucociliary clearance, and comorbid illnesses such as diabetes mellitus, alcoholism and malnutrition. It is also possible that abnormalities or deficiencies in surfactant proteins, alveolar macrophages and Toll-like receptors play a role in the pathogenesis of IPA in some patients with COPD [34-38].

It has been documented that chronic lung disease predisposes to colonisation of airways by Aspergillus spp., and it is possible, under certain circumstances, that this colonisation transforms 


\begin{tabular}{|c|c|}
\hline TABLE 1 & $\begin{array}{l}\text { Classical risk factors for invasive pulmonary } \\
\text { aspergillosis }\end{array}$ \\
\hline $\begin{array}{l}\text { Prolonged ne } \\
\text { Transplantatic } \\
\text { Prolonged (> } \\
\text { Haematologic } \\
\text { Chemotherap } \\
\text { Advanced All } \\
\text { Chronic gran }\end{array}$ & $\begin{array}{l}\text { ropenia }\left(<500 \text { cells } \cdot \mathrm{mm}^{-3} \text { for }>10 \text { days) }[10]\right. \\
\text { (highest risk is with lung transplantation and HSCT) }[11-14] \\
\text { weeks) and high-dose corticosteroid therapy }[10,15,16] \\
\text { I malignancy (risk is higher with leukaemia) }[5,7] \\
{[5,7,17]} \\
{[18-21]} \\
\text { omatous disease [22] }\end{array}$ \\
\hline
\end{tabular}

to an invasive disease [39]. In a review of 65 cases of IPA in patients with COPD who did not have the traditional risk factors for IPA [40], 75\% were on corticosteroid therapy for a median $2.6 \mathrm{yrs}$ prior to the diagnosis of IPA. The dose was increased in $34 \%$ of cases following hospitalisation (usually for the treatment of acute exacerbation of COPD) and prior to the diagnosis of IPA. Several patients in the study had low forced expiratory volume in $1 \mathrm{~s}$ or were described to have severe or very severe COPD. Only $43 \%$ of the cases had documented comorbidities including atypical mycobacteria, remote history of Mycobacterium tuberculosis, polymyalgia rheumatica, asthma, cirrhosis, diabetes mellitus, pneumoconiosis, Dressler's syndrome and lung cancer. 59 (91\%) patients died; the main cause of death was progressive respiratory failure. 31 (48\%) patients were reported to have received mechanical ventilation, and $13(20 \%)$ patients had evidence of disseminated IPA [40]. Potential explanations of the high mortality of IPA in these patients, also reported in other studies [41-43], are the delayed diagnosis secondary to low index of suspicion of this infection in this patient population, older age, poor pulmonary reserve and multiple comorbid illnesses. Since the clinical and radiological presentation of IPA in patients with COPD is nonspecific, to avoid delay in the diagnosis and management, a high index of suspicion is warranted. The isolation of Aspergillus spp. from a lower respiratory tract specimen should not be routinely dismissed as colonisation [40, 41].

IPA is also becoming an important infectious disease in intensive care unit (ICU) patients without the classical risk factors (neutropenia, leukaemia, HSCT), and the mortality is also devastating in these apparently less immunocompromised patients. Aspergillus spp. are isolated from lower respiratory patients, and in about half of these patients, this finding represents IPA [44-48]. In one retrospective study in a medical ICU, an incidence of invasive aspergillosis of $5.8 \%$ was found with pulmonary involvement in most cases. $70 \%$ of the cases were found in patients without leukaemia or cancer and the disease had a mortality rate exceeding 90\% [47]. In another study of 172 critically ill patients who had positive sputum samples for Aspergillus, 83 had invasive disease, and $60 \%$ of these patients had no classic risk factors for IPA [44]. Critically ill patients are prone to developing disturbances in immunoregulation during their stay in the ICU, which renders them more vulnerable to fungal infections. Risk factors such as COPD, systemic corticosteroid therapy, non-haematological malignancy, chronic renal disease, liver failure, diabetes mellitus, near-drowning, HIV infection, autoimmune diseases, malnutrition and extensive burns have been described [44-47, 49].
The clinical signs and symptoms of IPA and its radiographic features are often nonspecific in ICU patients. The finding of Aspergillus spp. in respiratory tract samples in these patients should not be routinely discarded as colonisation, even if these patients are immunocompetent [44]. Therefore, in order not to miss a critical window of therapeutic opportunity, adapted clinical diagnostic criteria should be used for this category and further diagnostic evaluation with early antifungal therapy should be considered once IPA is suspected in critically ill patients [50, 51]. IPA in this patient population carries an attributable mortality of $18.9 \%$ after adjusting for confounding factors [47]. A report suggests that the isolation of Aspergillus from lower respiratory tract samples was associated with a worse ICU outcome, regardless of whether the finding represented IPA or colonisation [52].

\section{Clinical presentation}

In most cases, Aspergillus is introduced to the lower respiratory tract by inhalation of the infectious spores. Less commonly, IPA may start in locations other than the lungs, such as sinuses, the gastrointestinal tract or the skin (via intravenous catheters, prolonged skin contact with adhesive tapes or burns) [53-56].

Symptoms are nonspecific and usually mimic bronchopneumonia: fever unresponsive to antibiotics, cough, sputum production and dyspnoea. Patients may also present with pleuritic chest pain (due to vascular invasion leading to thromboses that cause small pulmonary infarcts) and haemoptysis, which is usually mild, but can be severe. IPA is one of the most common causes of haemoptysis in neutropenic patients, and may be associated with cavitation that occurs with neutrophil recovery [57].

Aspergillus infection may also disseminate haematogenously to other organs, including the brain (fig. 2). This can lead to seizures, ring-enhancing lesions, cerebral infarctions, intracranial haemorrhage, meningitis and epidural abscesses. Other organs such as the skin, kidneys, pleura, heart, oesophagus and liver may be less frequently involved [58].

Aspergillus tracheobronchitis (ATB) is a unique feature of IPA. It represents isolated invasion of the tracheobronchial tree by Aspergillus spp. Predisposing factors for ATB are similar to those for IPA; however, certain patient groups are more likely to develop this entity. These include lung transplantation recipients, patients with AIDS and cancer patients with mediastinal involvement and/or treatment [59-61]. DENNING [62] proposed classifying ATB into three forms. Obstructive ATB is characterised by thick mucus plugs full of Aspergillus spp. without macroscopic bronchial inflammation. Pseudomembraneous ATB is characterised by extensive inflammation of the tracheobronchial tree and a membrane overlaying the mucosa containing Aspergillus spp. Ulcerative ATB is reserved to patients with limited involvement of the tracheobronchial tree, and is usually found at the suture line in lung transplantation recipients. Pseudomembraneous ATB is the most severe form and usually presents with cough and dyspnoea. Haemoptysis is not frequent. Radiological findings are not specific; however, evidence of segmental or lobar collapse may be present [61]. The diagnosis of ATB is usually made by the characteristic findings on bronchoscopy combined with microscopic analysis of respiratory specimens obtained during the procedure. The outcome 

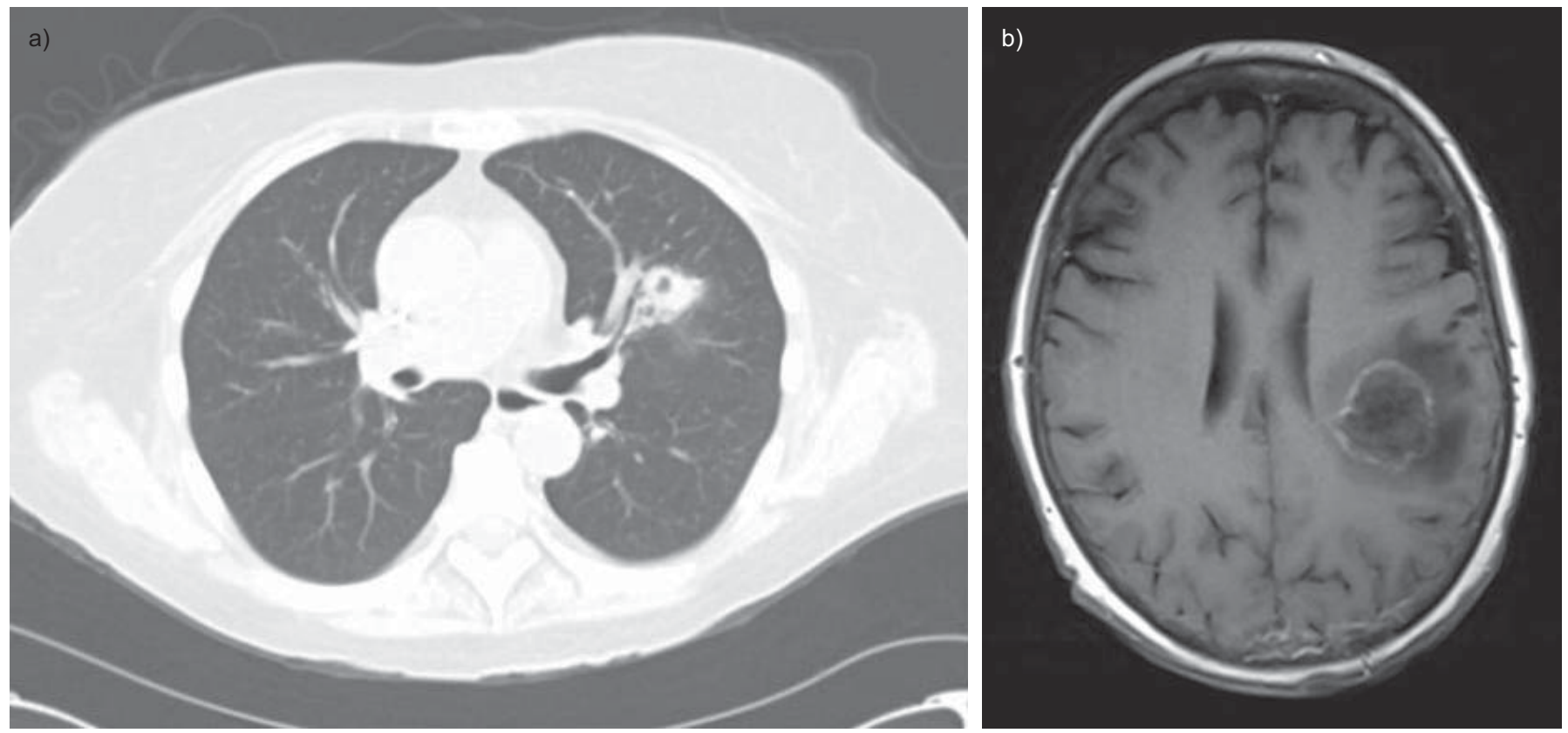

FIGURE 2. a) Chest computed tomography image showing left upper lobe cavitary lesion consistent with invasive pulmonary aspergillosis (IPA) in an allogeneic haematopoietic stem-cell transplantation recipient. b) Brain magnetic resonance image from the same patient showing left parietal ring enhancing lesion due to disseminated IPA.

of ulcerative ATB is generally favourable with antifungal therapy. On the other hand, the prognosis is poor in patients with pseudomembranous and obstructive ATB, with mortality reaching $78 \%$ [63]. The need for mechanical ventilation is a predictor of high mortality in these patients [63]. High index of suspicion of ATB, early diagnosis and prompt antifungal therapy may be associated with improved outcome [61].

\section{Diagnosis}

The diagnosis of IPA remains challenging. Early diagnosis of IPA in severely immunocompromised patients is difficult, and a high index of suspicion is necessary in patients with risk factors for invasive disease. The gold standard in the diagnosis of IPA is histopathological examination of lung tissue obtained by thoracoscopic or open-lung biopsy [64]. The presence of septate, acute, branching hyphae invading lung tissue along with a culture positive for Aspergillus from the same site is diagnostic of IPA (fig. 3). Histopathological examination also allows for the exclusion of other diagnoses, such as malignancy or nonfungal infectious diseases. The histopathological findings associated with IPA have been shown to differ according to the underlying host. In patients with allogeneic HSCT and GVHD, there is intense inflammation with neutrophilic infiltration, minimal coagulation necrosis and low fungal burden. In neutropenic patients, IPA is characterised by scant inflammation, extensive coagulation necrosis associated with hyphal angio-invasion, and high fungal burden. Dissemination to other organs is equally high in both groups [5].

The significance of isolating Aspergillus spp. in sputum samples depends on the immune status of the host. In immunocompetent patients, it almost always represents colonisation with no clinical consequences. In a study of 66 elderly hospitalised patients with Aspergillus isolated from the sputum, $92 \%$ were consistent with colonisation and only $4.5 \%$ had IPA [39]. Similar observations have been reported by others [65-67]. Therefore, in immunocompetent patients with Aspergillus isolated from the sputum, antifungal therapy is generally not indicated, but appropriate diagnostic studies should be considered to exclude IPA. However, isolation of an Aspergillus species from sputum is highly predictive of invasive disease in immunocompromised patients. Studies have shown that sputum samples that are positive for Aspergillus in patients with leukaemia, or in those who have undergone HSCT, have a positive predictive value of $80-90 \%$ $[66,68,69]$. Conversly, negative sputum samples do not rule out IPA; negative sputum studies have been noted in $70 \%$ of patients with confirmed IPA $[69,70]$. Blood cultures are rarely positive in patients with confirmed IPA [71].

Chest radiography is of little use in the early stages of disease because the incidence of nonspecific changes is high. Usual findings include rounded densities, pleural-based infiltrates suggestive of pulmonary infarctions, and cavitations. Pleural effusions are uncommon [72, 73]. Chest computed tomography $(\mathrm{CT})$, especially when combined with high-resolution images (HRCT), is much more useful (fig. 2). The routine use of HRCT of the chest early in the course of IPA leads to earlier diagnosis and improved outcomes [74, 75]. It also aids further diagnostic studies such as bronchoscopy and open-lung biopsy [76]. Typical chest CT scan findings in patients suspected to have IPA include multiple nodules and the halo sign, which is mainly seen in neutropenic patients early in the course of infection (usually in the first week) and appears as a zone of low attenuation due to haemorrhage surrounding the pulmonary nodule. Another late radiological sign is the air crescent sign, which appears as a crescent-shaped lucency in the region of the original nodule secondary to necrosis [73, 77]. Neither sign is sensitive or pathognomic of IPA. The halo sign may be found in many other situations: as a result of 

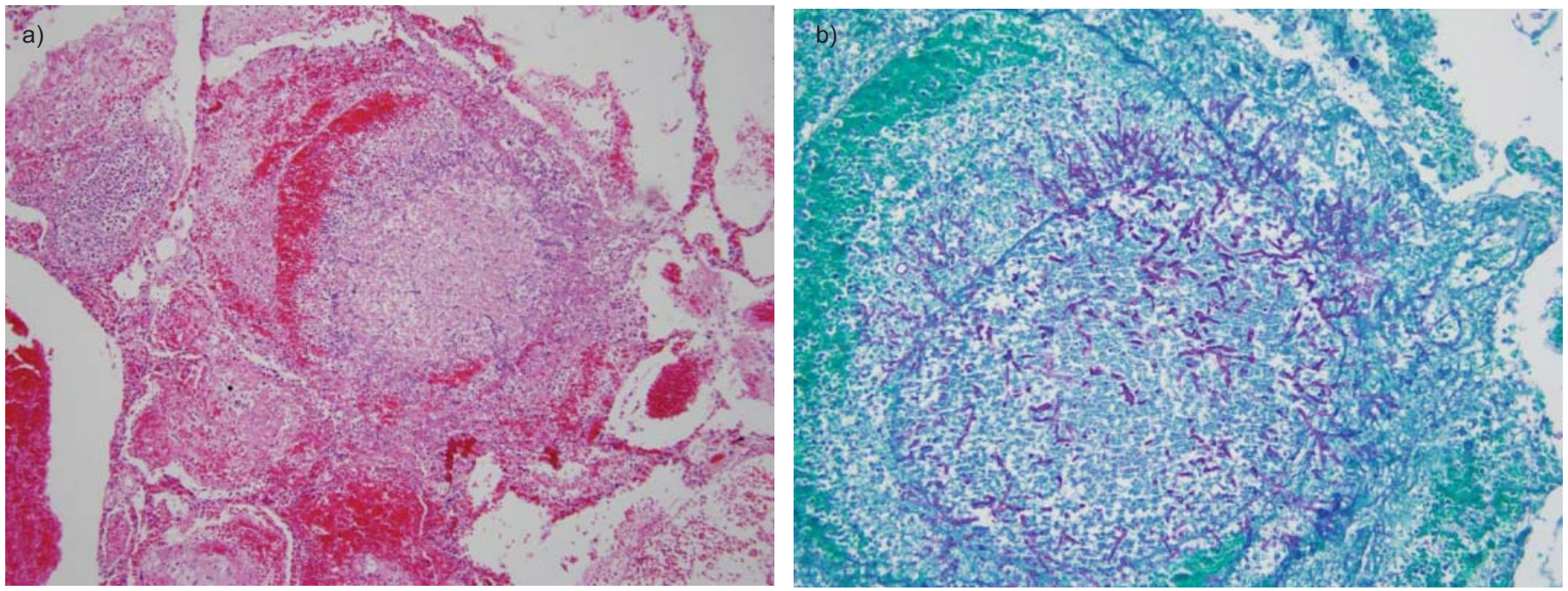

FIGURE 3. Invasive pulmonary aspergillosis. a) Pulmonary parenchyma with necrosis and pulmonary haemorrhage and Aspergillus hyphae (haematoxylin and eosin $100 \times$ ). b) Branching Aspergillus hyphae involving lung parenchyma (Grocott Methenamine silver fungus stain $200 \times$ ). Images courtesy of Dr. Mousa Al-Abbadi (East Tennessee State University, Johnson City, TN, USA)

metastasis, bronchoalveolar carcinoma, bronchiolitis obliterans organising pneumonia, eosinophilic pneumonia or other fungal infection [78]. GREENE [79] found that $94 \%$ of 235 patients with a confirmed diagnosis of IPA had at least one nodular region. In another report on HRCT chest findings in febrile neutropenic patients with pneumonia, the findings associated with IPA were ill-defined nodules $(67 \%)$, groundglass appearance $(56 \%)$, and consolidation (44\%) [80]. In a retrospective study of 45 patients, none of the early HRCT signs (nodule, consolidation, peribronchial infiltrates) predicted patient outcome or the development of pulmonary haemorrhage [81]. However, pulmonary haemorrhage is expected to occur in the presence of large cavitating lesions or consolidations located close to larger pulmonary vessels.

Bronchoscopy with bronchoalveolar lavage (BAL) is generally helpful in the diagnosis of IPA, especially in patients with diffuse lung involvement. The sensitivity and specificity of a positive result of BAL fluid are about $50 \%$ and $97 \%$, respectively, but this diagnostic yield of BAL in the diagnosis of IPA is not consistent, and much lower yields have been reported [66, 68, 82-86]. However, BAL is still a safe and useful tool in high-risk patients suspected to have IPA. In addition to obtaining samples for fungal stain and culture, it may also be useful in detecting Aspergillus antigens in the BAL fluid as well as excluding other infections. Transbronchial biopsies may be considered in selected patients.

It is always important to send the samples of the workup (sputum, BAL fluid or lung tissue) for culture as well as for histological examination. This is because a similar histological appearance to Aspergillus may be present with other fungal species, such as Scedosporium, Pseudallescheria and Fusarium [87]. In addition, there are many species of Aspergillus that may lead to IPA. While $A$. fumigatus is the most common, there are increasing reports of IPA in cancer patients due to other species such as Aspergillus niger, Aspergillus terreus and Aspergillus flavus [88-92]. Some of these species (such as A. terreus and Aspergillus nidulans) are resistant to amphotericin $B[89,92]$. In a review of 300 cases with proven IPA, A. terreus was the second commonest species, with a frequency of $23 \%$ of the cases. The risk factors and outcome for $A$. terreus infection were similar to those for $A$. fumigatus infection, but $A$. terreus was significantly more likely to be nosocomial in origin and more likely to be resistant to amphotericin B [91]. The new triazole antifungal agents such as voriconazole and posaconazole have significantly better efficacy against $A$. terreus $[89,90,93]$.

The most recent advances in the diagnosis of IPA are related to detecting Aspergillus antigens in body fluids, mainly galactomannan and (13)- $\beta$-D-glucan (both are cellular wall constituents). Galactomannan is a polysaccharide released by Aspergillus during growth. A double-sandwich ELISA for the detection of galactomannan in serum is the best characterised test and was approved by the US Food and Drug Administration (FDA) for the diagnosis of IPA with a threshold of $0.5 \mathrm{ng} \cdot \mathrm{mL}^{-1}$. It is reported that serum galactomannan can be detected several days before the presence of clinical signs, chest radiographic abnormalities or a positive culture. Thus, galactomannan detection may allow earlier confirmation of the diagnosis; it may also assist in the assessment of the evolution of infection during treatment if serial serum galactomannan values are obtained [94, 95].

To assess the accuracy of a galactomannan assay for diagnosing IPA, a meta-analysis was undertaken by PFEIFFER et al. [96] of 27 studies from 1996-2005. The cases were diagnosed with IPA according to the European Organization for Research on Treatment of Cancer/Mycoses Study Group (EORTC/MSG) criteria [97]. Overall, the assay had a sensitivity of $71 \%$ and specificity of $89 \%$ for proven cases of IPA. The negative predictive value was $92-98 \%$ and the positive predictive value was $25-62 \%$ [96]. PfeifFER et al. [96] also concluded that the galactomannan assay is more useful in patients who have a haematological malignancy or who have undergone allogeneic HSCT than in solid-organ transplant recipients or non-neutropenic patients.

Galactomannan is found in food and may be absorbed by the digestive tract, especially in patients with post-chemotherapy 
mucositis, resulting in a false-positive reaction. Also, medications such as $\beta$-lactam antibiotics (e.g. piperacillin/tazobactam) may be associated with a false-positive assay, while antifungal agents with activity against Aspergillus may lead to a falsenegative result [98-101].

One of the major limitations of the galactomannan test is the species-specificity of the assay: it is not possible to exclude involvement by other moulds such as Fusarium, Zygomycetes, and dematiaceous fungi [102]. Therefore, galactomannan detection does not remove the need for careful microbiological and clinical evaluations.

Galactomannan is detected in other body fluids such as BAL, urine, and cerebrospinal fluid (CSF), and there is evidence that these tests may become positive prior to clinical and radiological findings suggestive of IPA [102-105]. In one study, incorporating galactomannan and quantitative PCR assays into standard BAL fluid analysis appeared to enhance bronchoscopic identification of Aspergillus species as the cause of pulmonary disease in HSCT recipients [103]. Some prospective and retrospective studies have tried to assess the importance of galactomannan detection in BAL samples in different patient categories and situations; they found a higher sensitivity and similar specificity compared to serum samples. It also appeared that galactomannan detection in BAL fluid performed significantly better in diagnosing IPA than its detection in serum or BAL fungal stain and culture. Besides, it facilitated more rapid antifungal therapy among these patients [106-109].

Detection of galactomannan in the CSF for diagnosis of cerebral aspergillosis appears promising. A study [110] with a small number of patients suggested it might be diagnostic for high-risk patients with compatible neurological symptoms. Further studies on larger patient populations are necessary fully to evaluate the role of this test in the diagnosis of neurological aspergillosis.

PCR is another way to diagnose IPA by the detection of Aspergillus DNA in BAL fluid and serum. The sensitivity and specificity of PCR of BAL fluid samples are estimated to be 67$100 \%$ and 55-95\%, respectively [111], while for serum samples the sensitivity and specificity have been reported as $100 \%$ and $65-92 \%$, respectively [111-114]. However, PCR is often associated with false-positive results, because it does not discriminate between colonisation and infection. PCR for Aspergillus DNA detection remains restricted to highly specialised laboratories and cannot be considered as a routine clinical test.

Detection of serum (13)- $\beta$-D-glucan, a fungal cell wall constituent, has also received FDA approval and is a highly sensitive and specific test for invasive deep mycosis. This could be useful in immunocompromised patients, including those with candidiasis, fusariosis, and aspergillosis [115]. In one retrospective study [116], the sensitivity, specificity, and positive and negative predictive values for this test in diagnosing IPA were similar to those of galactomannan. The combination of the two tests showed improved specificity and positive predictive value compared with each test individually.

The role of serological studies in the diagnosis of IPA is evolving. Both galactomannan and (13)- $\beta$-D-glucan assays (but not PCR) were incorporated in the revised EORTC/MSG criteria for diagnosing IPA. However, their roles in different hosts, as surveillance tools, and their impact on the outcome for patients remain unclear. Ongoing prospective studies are attempting to address these issues, but until solid data are available, these tests should be considered as adjunct diagnostic studies. They should not replace appropriate clinical and radiological evaluation (and in selected cases, invasive procedures) to confirm the diagnosis of IPA.

The revised EORTC/MSG criteria (table 2) for the diagnosis of invasive fungal infections retained the original classifications of "proven," "probable," and "possible" invasive disease. However, the definition of "probable" has been expanded, whereas the scope of the category "possible" has been diminished. The category of proven invasive fungal disease can apply to any patient, regardless of whether or not the patient is immunocompromised, whereas the probable and possible categories are proposed for immunocompromised patients only. The revised definitions apply to immunocompromised patients but not necessarily to critically ill patients in the intensive care unit who, nonetheless, may develop possible or probable IPA [49]. The EORTC/MSG criteria are meant to serve as a guide for clinical and epidemiological research and thus do not need to be present in every patient in order to treat for IPA [97, 117, 118].

\section{Treatment}

Despite the introduction of several new antifungal agents, treatment of IPA remains difficult and mortality rates are still

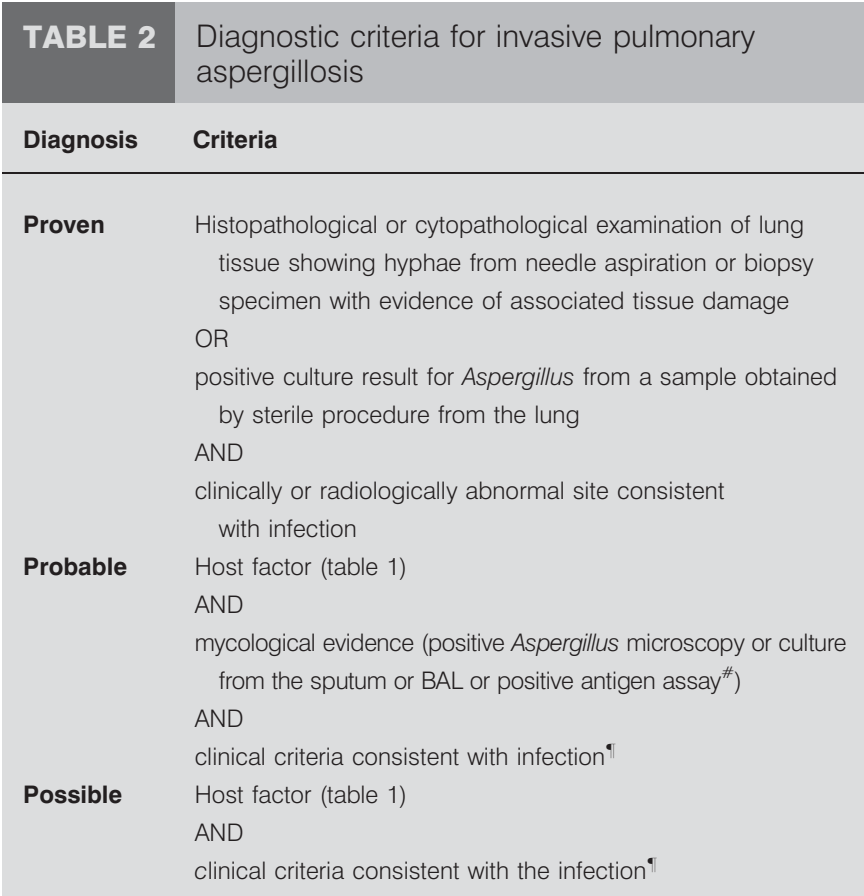

BAL: bronchoalveolarlavage. ${ }^{\#}$ : Positive antigen assay: galactomannan antigen detected in plasma, serum, BAL fluid or cerebrospinal fluid, or $\beta$-D-glucan detected in serum. $\because$ : Clinical criteria: new characteristic infiltrates on computed tomography imaging (dense, well-circumscribed lesion(s) with or without a halo sign, air-crescent sign, or cavity), tracheobronchitis seen by bronchoscopy, or noncharacteristic new infiltrates with a specific pulmonary symptom or sign (such as pleural rub, pleural pain, haemoptysis). Adapted from [117]. 
high (table 3). Therapy should be considered as soon as there is a clinical suspicion of IPA, and while a workup is under way. Amphotericin B has been the first line of therapy for IPA for many years, with a recommended dose $1-1.5 \mathrm{mg} \cdot \mathrm{kg}^{-1} \cdot \mathrm{day}^{-1}$. However, it can cause serious side-effects, including nephrotoxicity, electrolyte disturbances and hypersensitivity. To reduce these side-effects, newer lipid-based preparations of amphotericin B (like liposomal amphotericin B and lipid complex amphotericin B) have been introduced, but higher doses of the lipid formulations are needed for equivalent antifungal efficacy. A recent large randomised trial demonstrated no additional benefits of high-dose liposomal amphotericin B $\left(10 \mathrm{mg} \cdot \mathrm{kg}^{-1} \cdot \mathrm{day}^{-1}\right)$ compared with lower-dose liposomal amphotericin B regimens $\left(3 \mathrm{mg} \cdot \mathrm{kg}^{-1} \cdot \mathrm{day}^{-1}\right)$, and outcomes were generally good with the lower dose, suggesting utility of liposomal amphotericin B in the low doses, and therapeutic risk associated with excessive toxicities at the higher doses [124].

A new broad-spectrum triazole, voriconazole, has been approved as the initial treatment of invasive aspergillosis and is currently considered the treatment of choice in many patients with IPA [119-121]. In a large prospective, randomised, multicentre trial, voriconazole was compared to amphotericin B as the primary therapy for IPA [122]. Patients receiving voriconazole had a higher favourable response rate at week $12(53 \%$ versus $32 \%$ in patients receiving amphotericin B) and a higher 12 -week survival (71\% versus $58 \%$ ). Voriconazole is available in both intravenous and oral formulations. The recommended dose is $6 \mathrm{mg} \cdot \mathrm{kg}^{-1}$ twice daily intravenously on day 1 , followed by $4 \mathrm{mg} \cdot \mathrm{kg}^{-1} \cdot$ day $^{-1}$. After 7 days, switching to $200 \mathrm{mg}$ p.o. twice daily may be considered. Voriconazole has a milder side-effect profile and is much better tolerated than amphotericin B. The most frequent adverse effect is visual disturbances, described as blurred vision, photophobia and altered colour perception. Liver function test abnormalities and skin reactions are less common side-effects. However, voriconazole is associated with a significant number of drug-drug interactions, such as with cyclosporine, warfarin, terfenadine, carbamazepine, quinidine, rifampin, statins and sulfonylureas [119]. Since there is interindividual and intra-individual variability in voriconazole plasma levels, therapeutic drug monitoring for voriconazole should be considered in cases of refractory fungal infection or concerns about drug toxicity [147]. Another broad-spectrum triazole, posaconazole, is effective and safe as salvage therapy in patients with IPA refractory to standard antifungal therapy $[22,93,125]$.

Echinocandin derivatives such as caspofungin, micafungin and anidulafungin are also effective agents in the treatment of IPA refractory to standard treatment, or if the patient cannot tolerate first-line agents [126, 127]. While polyenes and azoles target the fungal cell membrane, echinocandins inhibit the (13)- $\beta$-D-glucan constituent of the fungal cell wall. Therefore, a combination antifungal therapy could be a strategy to treat refractory IPA $[148,149]$. There are in vitro and limited clinical studies (case reports and retrospective case series) that suggest a benefit from combining antifungal agents as salvage therapy in refractory IPA [149-152]. The combination of caspofungin and liposomal amphotericin B as a salvage therapy showed an overall response rate of $42 \%$, although in patients with documented progressive IPA, the response rate was only 18\% [149]. A survival advantage of voriconazole plus caspofungin compared with voriconazole alone was reported in one retrospective analysis of salvage therapy for IPA [151]. This combination was also compared with liposomal amphotericin B as primary therapy for IPA in solidorgan transplant recipients in a prospective, multicentre, observational study [153]. The combination was associated with improved survival in subsets of recipients with renal failure or A. fumigatus. Conversely, another report showed no difference in the response rate between patients who received micafungin alone or those who received it in combination with other antifungal agents as primary or salvage therapy for acute IPA [154]. Combination therapy of an echinocandin with either a lipid formulation of amphotericin B or triazole agent appears promising and should be considered in critically ill patients [155], but cannot be recommended for the routine treatment of primary IPA. Controlled randomised prospective studies are needed to document the value of this approach. Because galactomannan is covalently bound to (13)- $\beta$-D-glucan in the fungal cell wall, an initial increase in circulating galactomannan might be expected in patients treated with echinocandins, which inhibit the (13)- $\beta$-D-glucan constituent [156].

According to the recent statement of the American Thoracic Society for treating fungal infections in adults [123], the duration of IPA therapy should be individualised to the

TABLE 3 Treatment recommendations for pulmonary aspergillosis

Disease Primary treatment

Other treatments

Invasive pulmonary aspergillosis

Chronic necrotising aspergillosis

Aspergilloma

Allergic bronchopulmonary aspergillosis
Voriconazole [119-123]

Voriconazole $[120,123]$

Observation [123]
Alternative therapy: liposomal amphotericin B [124]

Continuation therapy: voriconazole or itraconazole [122, 123]

Salvage therapy: echinocandin or posaconazole [125-127]

Alternative therapy: itraconazole [128, 129]

Severe cases: intravenous voriconazole or liposomal amphotericin B [123, 128, 130]

Consider surgical resection [130]

Bronchial artery embolisation [131]

Surgical resection [132-135]

Consider itraconazole [136-138]

Itraconazole or voriconazole as steroid-sparing agents [143-146] 
patient's clinical and radiological response. The treatment is often prolonged, lasting several months to $>1$ yr. Prerequisites for discontinuing treatment include clinical and radiographic resolution, microbiological clearance and reversal of immunosuppression. Reinstating therapy in patients who have responded should be considered if immunosuppression is resumed, or if the patient requires additional cytotoxic therapy or another HSCT.

Surgical resection has generally a limited role in the management of patients with IPA, but it becomes important in cases with invasion of bone, burn wounds, epidural abscesses and vitreal disease [123]. It should also be considered in cases of massive haemoptysis, pulmonary lesions close to the great blood vessels or pericardium, or residual localised pulmonary lesions in patients with continuing immunosuppression or those who are expected to have immunosuppressive therapy in the future. Several reports have shown the relative efficacy and safety of surgical intervention, in addition to antifungal therapy, in these situations [75, 157-162].

Immunomodulatory therapy could be used to decrease the degree of immunosuppression and as an adjunct to antifungal therapy for the treatment of IPA. This includes colonystimulating factors, like granulocyte colony-stimulating factor (G-CSF) and granulocyte-macrophage colony-stimulating factor (GM-CSF), and interferon- $\gamma$. Colony-stimulating factors stimulate the bone marrow to produce more neutrophils, and have been shown to augment the phagocytic activity of neutrophils against fungi, including Aspergillus spp. [163165]. There is a theoretical advantage to adding these agents to the treatment of neutropenic patients suspected to have IPA. In one randomised study in patients receiving chemotherapy for acute myelogenous leukaemia, prophylaxis with GM-CSF led to a lower frequency of fatal fungal infections compared with placebo (1.9\% versus $19 \%$, respectively) and reduced overall mortality [166]. It is recommended to consider colonystimulating factors in neutropenic patients with serious infections, but there are no definitive studies that show benefit in patients with IPA [167]. Interferon- $\gamma$ is another cytokine that has been shown in vitro and in animal models to augment immunity by increasing neutrophil and monocyte activity against Aspergillus [164, 168, 169]. It has been used to decrease the risk of Aspergillus infection in patients with CGD [170]. Evidence on the value of adding interferon- $\gamma$ as an adjunct treatment of IPA is limited to case reports and small reports, and there are no guidelines on its role in the treatment of IPA [171]. There was a concern about the use of interferon- $\gamma$ in allogeneic HSCT recipients, since it may worsen GVHD; however, in a recent trial, GVHD actually improved during this therapy [172].

Granulocyte transfusion is another potential supportive therapy, especially for patients with prolonged neutropenia and life-threatening infections refractory to conventional therapy. It has been shown that it is safe for potential donors to donate neutrophils by granulocytophoresis, but there are no randomised studies that prove the benefit of adjuvant granulocyte transfusion in the treatment of IPA [173]. It is also important in patients with IPA, whenever possible, to decrease the dose of systemic corticosteroids and immunosuppressive agents.
The management of IPA is difficult, and an important approach to this problem is prophylaxis in patients at increased risk for IPA. Avoiding the hospitalisation of patients in areas where there is construction and the use of high-efficiency particulate air (HEPA) filtration, with or without laminar air flow ventilation, have both proven useful [174]. A meta-analysis suggested that itraconazole was effective in preventing fungal infections in neutropenic patients [175]. Recent studies confirmed the efficacy of posaconazole as IPA prophylaxis in patients with acute myelogenous leukaemia, myelodysplastic syndrome or HSCT [176-178]. Currently, chemoprophylaxis trials using other antifungal agents (such as voriconazole, caspofungin, micafungin, and inhaled amphotericin B formulation) are under way in highrisk patients [123].

\section{CHRONIC NECROTISING ASPERGILLOSIS}

CNA, also called semi-invasive or subacute invasive aspergillosis, was first described by GEFTER et al. [179] and BINDER et al. [130] in 1981. It is an indolent, cavitary and infectious process of the lung parenchyma secondary to local invasion by Aspergillus species, usually A. fumigatus [128]. In contrast to IPA, CNA runs a slowly progressive course over weeks to months, and vascular invasion or dissemination to other organs is unusual. This syndrome is rare, and the available literature is based on case reports and small case series [128, 130, 179].

\section{Risk factors}

CNA usually affects middle-aged and elderly patients with altered local defences, associated with underlying chronic lung diseases such as COPD, previous pulmonary tuberculosis, thoracic surgery, radiation therapy, pneumoconiosis, cystic fibrosis, lung infarction or sarcoidosis [180]. It may also occur in patients who are mildly immunocompromised due to diabetes mellitus, alcoholism, chronic liver disease, low-dose corticosteroid therapy, malnutrition, or connective tissue diseases such as rheumatoid arthritis and ankylosing spondylitis [130]. Mannose-binding lectin polymorphism may play a role in the pathogenesis of CNA [181]. It may be difficult to distinguish CNA from aspergilloma, especially if a previous chest radiograph is not available [182]. However, in CNA there is local invasion of the lung tissue and a pre-existing cavity is not needed, although a cavity with a fungal ball may develop in the lung as a secondary phenomenon due to destruction by the fungus. In a report of aspergillomas in AIDS patients, progression over time was seen, with considerable morbidity and some mortality [182]. This probably reflects the possibility that an aspergilloma may invade the cavity wall, causing local parenchyma destruction, as seen in patients with CNA [128]. Due to this overlap between the CNA and aspergilloma, some authors put them in one group called chronic cavitary pulmonary aspergillosis which is primarily a non- or semiinvasive disease that is seen mainly in nonimmunocompromised patients with chronic lung diseases [183].

\section{Clinical presentation and diagnosis}

Patients frequently complain of constitutional symptoms such as fever, malaise, fatigue, and weight loss of 1-6 months' duration, in addition to chronic productive cough and haemoptysis, which varies from mild to severe [182]. Occasionally, CNA may be asymptomatic. 
Imaging studies, such as chest radiograph and chest CT scan, usually show consolidation, pleural thickening and cavitary lesions in the upper lung lobes. Aspergilloma may be seen in nearly $50 \%$ of patients [130]. The adjacent pleural thickening may progress to form a broncho-pleural fistula, so it is considered an early indication of a locally invasive process $[179,184]$. Characteristically, these radiological findings tend to progress over weeks to months [184].

The vast majority of patients with CNA have positive serum immunoglobuling (Ig)G antibodies to A. fumigatus, but this varies over time and may be negative at some points in the course of CNA [182]. Immediate skin reactivity for Aspergillus antigens is another helpful, but not diagnostic, test. Culture of sputum and bronchoscopy samples is usually positive for Aspergillus spp. [182].

Confirmation of the diagnosis requires a histological demonstration of tissue invasion by the fungus and the growth of Aspergillus species on culture. Pathologically, CNA is characterised by necrosis of lung tissue, acute or chronic inflammation of the cavity wall and presence of hyphae consistent with Aspergillus species [185]. The yield of transbronchial biopsy specimens or percutaneous aspirates is relatively poor, and a thoracoscopic or open-lung biopsy is rarely performed in these patients. As a result, confirmation of the diagnosis is commonly delayed, which may contribute to the morbidity and mortality associated with CNA. The combination of characteristic clinical and radiological findings and either serological results positive for Aspergillus or the isolation of Aspergillus from respiratory samples is highly indicative of CNA [186]. DENNING et al. [186] have proposed criteria for diagnosis of chronic pulmonary aspergillosis, including CNA (table 4).

\section{Treatment}

The mainstay of treatment for CNA is the antifungal therapy (table 3). Amphotericin B was initially used in doses of 0.5$1 \mathrm{mg}^{-1} \cdot \mathrm{kg}^{-1} \cdot \mathrm{day}^{-1}\left(4-5 \mathrm{mg} \cdot \mathrm{kg}^{-1} \cdot \mathrm{day}^{-1}\right.$ for the lipid formulation) with favourable results $[128,130]$. Itraconazole later became an effective alternative to the relatively toxic amphotericin B [128, 129]. More recently, voriconazole has emerged as a primary therapy for CNA. In a recent prospective study, where voriconazole $200 \mathrm{mg}$ was given twice daily for a period of 4 24 weeks as primary or salvage therapy for 39 patients with CNA [120], a complete or partial response was seen in $43 \%$ of patients, and improvement or stability was seen in $80 \%$. The recent statement of the American Thoracic Society favours giving either voriconazole or itraconazole for mild to moderate disease until resolution or stabilisation of the clinical and radiographic manifestations, while in patients with severe disease, initial therapy with intravenous amphotericin B or intravenous voriconazole should be considered [123].

Evaluation of the response to treatment is best done by following clinical, radiological, serological and microbiological parameters [182]. Useful parameters of response include weight gain and enhanced energy level, improved pulmonary symptoms, falling inflammatory markers and total serum IgE level, improvement in paracavitary infiltrates, and eventually a reduction in cavity size [182].

Surgical resection has a minor role in the treatment of CNA, being reserved for healthy young patients with focal disease and good pulmonary reserves, patients not tolerating antifungal therapy and patients with residual localised but active disease despite adequate antifungal therapy. BINDER et al. [130] reported that $90 \%$ of patients who underwent surgical resection had good responses, but surgery was associated with significant post-operative complications.

The reported mortality of CNA varies widely and may be limited by incomplete follow-up [128]. Mortality was 39\% in American reports, but less than $10 \%$ in European reports using itraconazole [128].

\section{ASPERGILLOMA}

Aspergilloma is the most common and best-recognised form of pulmonary involvement by Aspergillus species, and it usually develops in a pre-existing cavity in the lung. The aspergilloma (fungus ball) is composed of fungal hyphae, inflammatory cells, fibrin, mucus, and tissue debris. The most common species of Aspergillus recovered from such lesions is A.fumigatus; however, other fungi, such as Zygomycetes and Fusarium, may cause the formation of a fungal ball. Many cavitary lung diseases are complicated by aspergilloma, including tuberculosis, sarcoidosis, bronchiectasis, bronchial cysts and bullae, ankylosing spondylitis, neoplasm, and pulmonary infection $[187,188]$. Of these, tuberculosis is the most common [189]. In a study of 544 patients with pulmonary cavities secondary to tuberculosis, $11 \%$ had radiological evidence of aspergilloma [190]. Less frequently, aspergilloma has been described in cavities caused by other fungal infections [191, 192]. It is thought that inadequate

\section{TABLE 4 Diagnostic criteria for chronic necrotising aspergillosis}

\section{Diagnostic criteria Characteristics}

$\begin{array}{ll}\text { Clinical } & \text { Chronic (>1 month) pulmonary or systemic symptoms, including at least one of: weight loss, productive cough or haemoptysis } \\ \text { Radiological } & \begin{array}{l}\text { No overt immunocompromising conditions (e.g. haematological malignancy, neutropenia, organ transplantation) } \\ \text { Cavitary pulmonary lesion with evidence of paracavitary infiltrate }\end{array} \\ \text { New cavity formation, or expansion of cavity size over time } & \begin{array}{l}\text { Elevated levels of inflammatory markers (C-reactive protein, plasma viscosity or erythrocyte sedimentation rate). Isolation of Aspergillus spp. from } \\ \text { pulmonary or pleural cavity, or positive serum Aspergillus precipitin test. Exclusion of other pulmonary pathogens, by results of appropriate } \\ \text { cultures and serological tests, that are associated with similar disease presentation, including mycobacteria and endemic fungi }\end{array} \\ \text { Adapted from [186]. }\end{array}$


drainage can facilitate the growth of Aspergillus on the walls of these cavities.

The fungus ball may move within the cavity, but it does not usually invade the surrounding lung parenchyma or blood vessels, although exceptions have been noted [193, 194]. The lesion remains stable in the majority of cases, but it may decrease in size or resolve spontaneously without treatment in $10 \%$ of cases [195]. Rarely, the aspergilloma may increase in size.

\section{Clinical presentation}

Most patients with aspergilloma are asymptomatic. When symptoms are present, most patients experience mild haemoptysis, but severe and life-threatening haemoptysis may occur, particularly in patients with underlying tuberculosis [196]. The mortality rate from haemoptysis related to aspergilloma ranges between $2-14 \%$ [197-201]. The source of bleeding is usually the bronchial blood vessels, and it may be caused by local invasion of blood vessels lining the cavity, endotoxins released from the fungus, or mechanical irritation of the exposed vasculature inside the cavity by the moving fungus ball [193, 202, 203]. Less commonly, patients may develop cough, dyspnoea that is probably more related to the underlying lung disease and fever that could be secondary to the underlying disease or bacterial superinfection.

Risk factors for poor prognosis of aspergilloma include the severity of the underlying lung disease, increase in size or number of lesions as seen on chest radiographs, immunosuppression (including corticosteroid therapy and HIV infection), increasing Aspergillus-specific IgG titres, recurrent large volume haemoptysis and underlying sarcoidosis [204].

\section{Diagnosis}

The diagnosis of pulmonary aspergilloma is usually based on clinical and radiographic features along with serological or microbiological evidence of Aspergillus spp. Chest radiography is useful in demonstrating the presence of a mass in a pre-existing cavity. Aspergilloma appears as an upper-lobe, mobile, intra-cavitary mass with an air crescent in the periphery [205]. A change in the position of the fungus ball after moving the patient from supine to prone position is an interesting but variable sign [206]. Chest CT scan may be necessary to visualise aspergilloma that is not apparent on chest radiograph [206] (fig. 4). These radiological appearances may be seen in other conditions such as neoplasm, abscess, hydatid cyst and granulomatosis with polyangiitis (Wegener's granulomatosis). Aspergilloma may also coexist with any of the above-mentioned conditions [207, 208]. Sputum cultures for Aspergillus spp are positive only in 50\% of cases [209]. Serum IgG antibodies to Aspergillus are positive in most cases but may be negative in patients on corticosteroid therapy [194]. Aspergillus antigen has been recovered from the BAL fluid of patients with aspergilloma, but the diagnostic value of this test is variable [210, 211].

\section{Treatment}

Treatment is considered only when patients become symptomatic, usually with haemoptysis (table 3). There is no consensus on the best treatment approach. Inhaled, intracavitary and endobronchial instillations of antifungal agents have been tried and reported in small numbers of patients, but

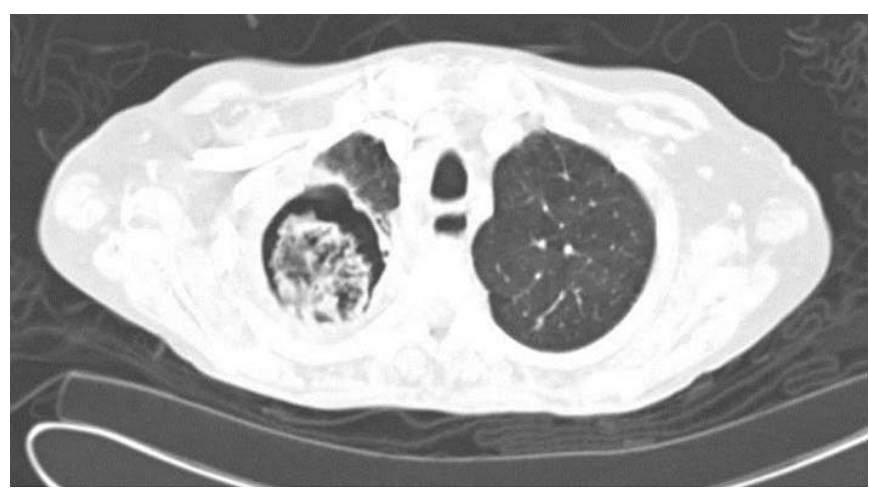

FIGURE 4. Chest computed tomography image showing a right upper lobe aspergilloma in a patient with sarcoidosis.

without consistent success $[200,212,213]$. CT-guided percutaneous administration of amphotericin B can be effective for aspergilloma, especially in patients with massive haemoptysis, and can lead to resolution within few days [214, 215]. The role of intravenous amphotericin B is uncertain; small studies failed to show a benefit [216].

Itraconazole may be useful in the management of selected patients with aspergilloma because it has a high tissue penetration. Oral itraconazole has been used with radiographic and symptomatic improvement in one-half to two-thirds of patients. Occasionally patients have a complete response [136-138]. In one study, significant itraconazole levels within the aspergilloma cavities were demonstrated after using the standard dose of itraconazole (100-200 mg.day $\left.{ }^{-1}\right)$ [217]. The major limitation of itraconazole is that it works slowly and would not be useful in cases of life-threatening haemoptysis [210].

Surgical resection of the cavity and removal of the fungus ball is usually indicated in patients with recurrent haemoptysis, if their pulmonary function is sufficient to allow surgery. It is associated with relatively high mortality rates, ranging from 7$23 \%$ [132-135, 197, 198, 203]. The most common causes of death post-operatively are severe underlying lung disease, pneumonia, acute myocardial infarction, and IPA $[135,200]$. Other post-operative complications include haemorrhage, residual pleural space, bronchoalveolar fistula, empyema and respiratory failure.

Bronchial artery embolisation should be considered as a temporary measure in patients with life-threatening haemoptysis, since haemoptysis usually recurs as a result of massive collateral blood vessels [131]. The role of newer antifungal azoles such as voriconazole in the treatment of aspergilloma has yet to be determined.

\section{ALLERGIC BRONCHOPULMONARY ASPERGILLOSIS}

Allergic bronchopulmonary aspergillosis (ABPA) is a pulmonary disease that results from hypersensitivity to Aspergillus antigens, mostly due to $A$. fumigatus. The majority of cases occur among people with asthma or cystic fibrosis. It is estimated that $2 \%$ of asthmatics, and $7-14 \%$ of corticosteroiddependent asthmatics have ABPA. Also the incidence of ABPA is higher in patients with atopy [218]. In the case of cystic fibrosis, $1-15 \%$ of patients may develop ABPA [219-222]. 
Sensitisation to Aspergillus antigens is an important phenomenon in asthmatics, especially those with atopy. In a metaanalysis of 21 studies, the prevalence of sensitisation to Aspergillus antigens in selected patients with asthma was $28 \%$ [223]. The prevalences of ABPA in patients with asthma and those with Aspergillus hypersensitivity were $12.9 \%$ and $40 \%$, respectively. In addition to increasing the risk of ABPA, sensitisation to Aspergillus antigens appears to increase the severity of asthma. In a study of 105 patients with asthma, $28.5 \%$ of patients were sensitised to Aspergillus antigens [224]. About one-third of this group had ABPA. Patients with sensitisation to Aspergillus antigens had significantly more severe airflow obstruction and more prescriptions for oral corticosteroids. Similar findings were reported in another study from Cleveland (OH, USA) and London (UK) [225]. These observations suggest that it is crucial to screen asthmatic patients for sensitisation to Aspergillus antigens and to monitor these patients more closely and exclude the presence of ABPA. Among patients with cystic fibrosis, ABPA is more commonly seen in those who are males, have a history of asthma or atopy, have lower lung function or have Pseudomonas in sputum cultures [220].

The pathogenesis of ABPA is not completely understood. There does not appear to be a correlation between Aspergillus load in the environment and the development of ABPA [226]. Many immune responses appear to be involved, including Aspergillus-specific IgE-mediated type I hypersensitivity reactions, specific IgG-mediated type III hypersensitivity reactions, and abnormal T-lymphocyte responses [227-230].

\section{Clinical presentation and diagnosis}

ABPA is usually suspected on clinical grounds. The diagnosis is confirmed by radiological and serological testing. Almost all patients have clinical asthma, and patients usually present with episodic wheezing, expectoration of sputum containing brown plugs, pleuritic chest pain, and fever [231]. Chest radiograph may be normal in the early stages of the disease. During acute exacerbations, fleeting pulmonary infiltrates are a characteristic feature of the disease that tend to appear in the upper lobe and are central in location. Due to mucoid impaction of the airways, there may be transient areas of opacification, which may present as band-like opacities emanating from the hilum with rounded distal margin (gloved finger appearance) [232]. The "ring sign" and "tram lines" are radiological signs that represent the thickened and inflamed bronchi and may be seen in chest radiography. At later stages, central bronchiectasis and pulmonary fibrosis may develop. Chest HRCT is helpful for better defining bronchiectasis and is also more sensitive in demonstrating the above changes (fig. 5). Typically, total serum IgE is elevated (usually $>1000 \mathrm{IU} \cdot \mathrm{mL}^{-1}$ ), and sputum cultures reveal Aspergillus spp. Serum IgE could be used as a marker for flare-ups and response to therapy [233]. However a positive sputum culture is not necessary to diagnose ABPA. Immediate skin test reactivity to A. fumigatus antigens and elevated levels of serum $\operatorname{IgG}$ and $\operatorname{IgE}$ antibodies to Aspergillus are usually documented [227]. Although pulmonary function tests are not characteristic of ABPA, they usually show reversible obstructive lung disease that may become irreversible in later stages. Restrictive lung disease with reduction in diffusion capacity may be observed during acute exacerbations

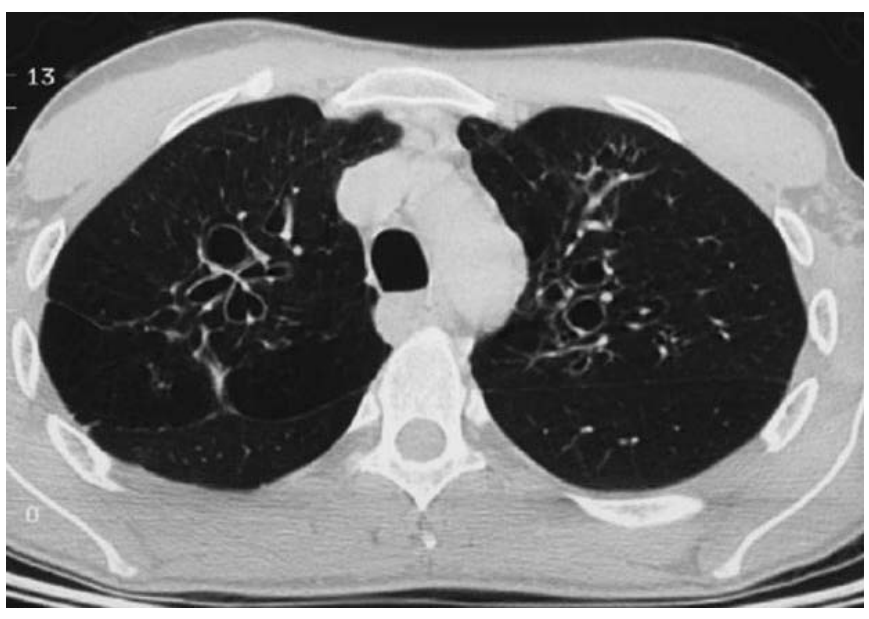

FIGURE 5. Chest computed tomography image showing central bronchiectasis in a patient with allergic bronchopulmonary aspergillosis.

or late stages. Pulmonary function tests may be useful in following up the progress of disease over time. Bronchoscopy is not necessary for the diagnosis of ABPA; however, if performed, BAL may show increased levels of eosinophils and $\operatorname{IgE}$ concentration. Aspergillus may rarely be detected on fungal stain or culture [234].

Lung biopsies are rarely performed since ABPA is usually suspected on clinical rounds [230]. In one pathological study, 18 specimens were taken from patients diagnosed with ABPA and the most significant findings were involvement of the bronchi and bronchioles, with bronchocentric granulomas in 15 specimens and mucoid impaction in 11 [235]. Other findings included granulomatous inflammation consisting of palisading histiocytes surrounded by lymphocytes, plasma cells, and eosinophils. Fungal hyphae were seen, but without evidence of tissue invasion [235]. ROSENBERG et al. [231] and GREENBERGER et al. [233] have standardised the criteria for the diagnosis of ABPA (table 5), not all of which need to be present for the diagnosis to be made.

As delayed treatment may result in irreversible pulmonary damage, early detection and treatment of ABPA before the development of all clinical symptoms and bronchiectasis is paramount. Patients with ABPA can be subdivided into two groups: patients with or without central bronchiectasis (CB)

\begin{tabular}{l} 
TABLE 5 Diagnostic criteria for allergic bronchopulmonary \\
aspergillosis \\
Asthma \\
Immediate skin reactivity to Aspergillus \\
Serum precipitins to Aspergillus fumigatus \\
Increased serum IgE and IgG to Aspergillus fumigatus \\
Total serum IgE $>1000 \mathrm{IU} \cdot \mathrm{mL}^{-1}$ \\
Current or previous pulmonary infiltrates \\
Central bronchiectasis \\
Peripheral eosinophilia (1000 cells· $\mu \mathrm{L}^{-1}$ ) \\
\hline Ig: immunoglobulin. Adapted from $[231,233]$.
\end{tabular}


(ABPA-CB and ABPA-seropositive, respectively) [1]. The minimum essential criteria to diagnose patients with ABPA$\mathrm{CB}$ include asthma, immediate skin reactivity to Aspergillus antigens, serum IgE level $>1,000 \mathrm{ng} \cdot \mathrm{mL}^{-1}$ and central bronchiectasis. The minimum criteria to diagnose ABPA-seropositive patients include asthma, immediate skin reactivity to Aspergillus antigens, serum $\mathrm{IgE}>1,000 \mathrm{ng} \cdot \mathrm{mL}^{-1}$, history of pulmonary infiltrates and elevated levels of serum IgE or IgG antibodies to A. fumigatus [236].

PATTERSON et al. [237] have also subdivided ABPA into five stages on the basis of clinical course, which helps to guide the management of the disease [237]. These stages do not need to occur in order. The first four are potentially reversible with no long-term sequel. Stage I, the acute stage, is the initial acute presentation with asthma, elevated IgE level, peripheral eosinophilia, pulmonary infiltrates, and $\operatorname{IgE}$ and IgG antibodies to $A$. fumigatus. In practice, patients are seldom identified in this stage. In stage II, the remission stage, the IgE falls but usually remains elevated, eosinophilia is absent, and the chest radiograph is clear. Serum IgG antibodies to Aspergillus antigen may be slightly elevated. Stage III, the exacerbation stage, is the recurrence of the same findings as in stage I in patients known to have ABPA. IgE rises to at least double the baseline level. Stage IV, the corticosteroid-dependent stage, occurs in patients who have asthma dependent on chronic use of high-dose corticosteroid therapy. Exacerbations are marked by worsening asthma, radiographic changes and a potential increase in IgE levels. Frequently, the chest CT scan will show central bronchiectasis. Unfortunately, most patients are diagnosed at this stage [238]. In stage V, the fibrotic stage, bronchiectasis and fibrosis develop usually leading to irreversible lung disease. Patients in this stage may present with dyspnoea, cyanosis, rales, and cor pulmonale. Clubbing may be present. The serum IgE level and eosinophil count might be low or high. Fortunately, few patients progress to this stage.

\section{Treatment}

Treatment of ABPA aims to treat acute exacerbations of the disease and limit progressive lung disease and bronchiectasis. Oral corticosteroids are the main treatment for ABPA (table 3). They suppress the hypersensitivity and inflammatory response provoked by A. fumigatus rather than eradicating the organism. Treatment with corticosteroids leads to the relief of bronchospasm, the resolution of radiographic infiltrates and a reduction in serum total $\mathrm{IgE}$ and peripheral eosinophilia [139, 140]. 2 weeks of daily therapy of oral prednisone $\left(0.5 \mathrm{mg} \cdot \mathrm{kg}^{-1} \cdot \mathrm{day}^{-1}\right)$, followed by gradual tapering, has been recommended for new ABPA-related infiltrates [141, 142]. The duration of therapy should be individualised according to the patient's clinical condition. However, most patients require prolonged low-dose corticosteroid therapy to control their symptoms and decrease the rate of relapse [141, 142]. Total serum $\operatorname{IgE}$ serves as a marker of ABPA disease activity. It should be checked 6-8 weeks after the initiation of therapy and then every 8 weeks for 1 year after that to determine a baseline range for each individual patient [239]. Inhaled corticosteroids may help to control symptoms of asthma, but small studies have failed to demonstrate the efficacy of inhaled corticosteroids in preventing the progression of lung damage in patients with ABPA [240, 241].
Several studies have been done on the utility of the antifungal agent itraconazole in the management of patients with ABPA. It has been effective in improving symptoms, facilitating weaning from corticosteroids, decreasing Aspergillus titres and improving radiographic abnormalities and pulmonary function [210]. A randomised, double-blind, placebo-controlled trial of itraconazole $200 \mathrm{mg}$ twice daily for 16 weeks for patients with ABPA already receiving corticosteroids was recently conducted by STEVENS et al. [143]. $46 \%$ of patients treated with itraconazole achieved significant response, defined as a reduction of at least $50 \%$ in the corticosteroid dose, decrease of at least $25 \%$ in the serum $\operatorname{IgE}$ concentration, and one of the following: a $25 \%$ improvement in exercise tolerance or pulmonary function test results or partial or complete resolution of pulmonary infiltrates. Of note, however, itraconazole may augment the activity of corticosteroids via inhibition of their metabolism, which may lead to abnormal adrenocorticotropic hormone stimulation and adrenal insufficiency [242]. Recently, voriconazole has also been tried in the treatment of ABPA and showed a favourable therapeutic response in the few case reports available [144-146]. In one study of small number of children with cystic fibrosis and ABPA, voriconazole treatment demonstrated significant clinical and serological improvements [243]. Randomised trials are needed to assess the efficacy of voriconazole in the management of ABPA. Few case reports have described the beneficial use of the anti-IgE monoclonal antibody (omalizumab) in patients with ABPA. They have shown rapid improvement of the respiratory symptoms and lung function [244, 245].

\section{PULMONARY ASPERGILLUS OVERLAP SYNDROMES}

The above-mentioned Aspergillus syndromes may co-exist (e.g. fungal balls in patients with ABPA) or may progress from one entity to another (e.g. IPA in a patient with ABPA) (fig. 6). These Aspergillus overlap syndromes have been reported in case reports or small case series. The proposed mechanisms for the development of Aspergillus overlap syndromes include coincidence, the presence of severe underlying lung disease (e.g. a patient with aspergilloma who develops CNA), corticosteroid therapy (IPA in a patient with aspergilloma or ABPA), or Aspergillus fungal load. It is also possible that genetic factors may predispose patients to progress from one form of aspergillosis to another. For example, CFTR gene mutation may lead to ABPA, and mannose-binding lectin gene mutations may result in CNA or IPA. Viral illnesses (in a patient with ABPA or aspergilloma) have been rarely reported as a risk factor for IPA [183].

The emergence of fungal balls in patients with ABPA has been reported infrequently in the literature. It may occur as an early event as well as a late phenomenon. In early cases, the bronchiectatic areas affected by ABPA may enlarge to form cavities that colonise with Aspergillus spp., creating fungal balls that may present as haemoptysis and/or a cavitary mass [142, 246]. The knowledge that aspergillomas may develop in patients with ABPA helps avoid unnecessary invasive procedures to rule out alternative aetiologies, such malignancy or tuberculosis. Fungal balls may also be a late finding in patients with fibrosis and cavitation associated with long-standing or poorly treated ABPA. In some of these patients, this aspergilloma could be due to concomitant fibrocavitary disease [247] (such as tuberculosis) 


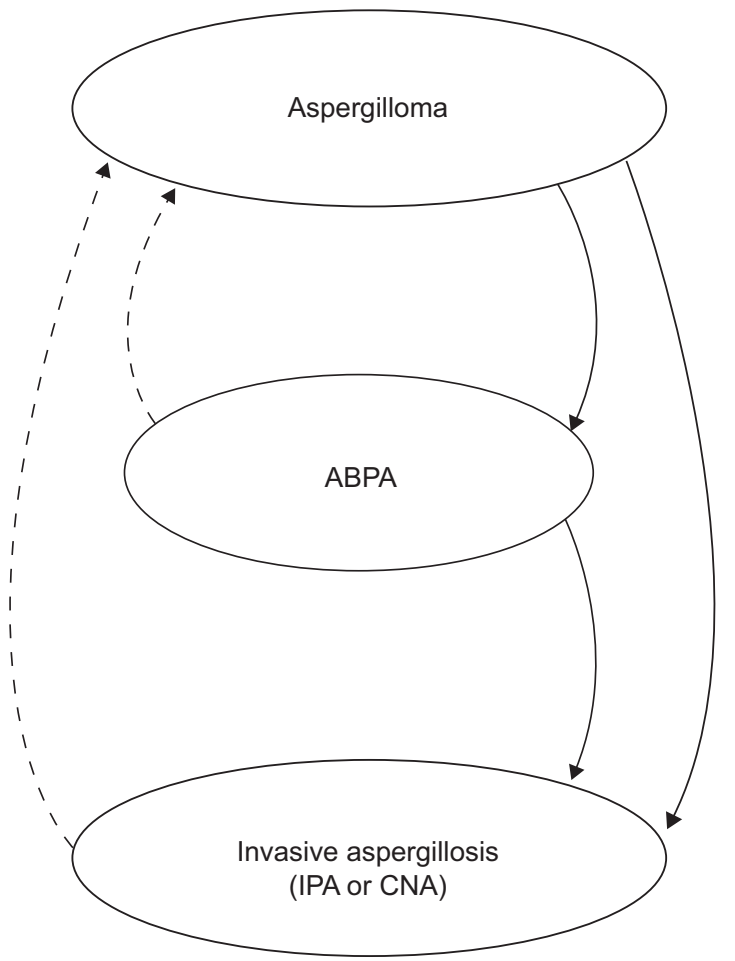

FIGURE 6. Clinical scenarios of Aspergillus overlap syndromes in the lungs. ABPA: allergic bronchopulmonary aspergillosis; IPA: invasive pulmonary aspergilIosis; CNA: chronic necrotising aspergillosis.

that was activated by steroid therapy for ABPA which would accelerate the fibrocavitary changes and the development of fungal balls [142, 248]. In some cases, fungal balls may precede ABPA, and may also have a role in the pathogenesis of ABPA in susceptible hosts. There are reports of patients who developed aspergilloma or CNA associated with pre-existing fibrocavitary disease (such as tuberculosis or sarcoidosis) and later developed ABPA [249]. It is possible that the overgrowth of Aspergillus species in these cavities triggers a hypersensitivity reaction in susceptible patients, leading to ABPA. Concurrent ABPA and aspergilloma is likely to increase the severity of the disease with more frequent exacerbations of asthma and possibly increased risk of haemoptysis [250]. Such patients should be monitored carefully and antifungal therapy or resection of the aspergilloma may be necessary in symptomatic patients [250, 251].

IPA in patients with ABPA has been reported sporadically in the literature. In some reports, the invasion by Aspergillus species is restricted to the tissues surrounding the bronchiectatic segments with granulomatous reaction [252-254]. Some of these cases are more likely to represent the semi-invasive form of CNA rather than IPA due to their chronic courses. This local invasion by Aspergillus probably develops as a result of chronic immunosuppression because of corticosteroids and/or the presence of underlying chronic lung disease. Disseminated IPA has rarely been described in patients with ABPA [255, 256]. Few case reports describe patients with cystic fibrosis on high-dose corticosteroids who acquire a viral infection, like influenza, predisposing them to IPA [257, 258]. However, given the paucity of literature about these cases there are no validated predictors for the development of IPA in patients with ABPA.

Aspergillus species may also play a role in the pathogenesis of other pulmonary conditions that are not part of the characteristic diseases caused by this fungus. Although these conditions are thought to develop independently from the Aspergillus species, there is evidence that the fungus may be implicated in some cases. These diseases include IgE-mediated asthma, hypersensitivity pneumonitis, mucoid impaction in bronchus and bronchocentric granulomatosis.

\section{STATEMENT OF INTEREST}

None declared.

\section{REFERENCES}

1 Soubani AO, Chandrasekar PH. The clinical spectrum of pulmonary aspergillosis. Chest 2002; 121: 1988-1999.

2 Zmeili OS, Soubani AO. Pulmonary aspergillosis: a clinical update. QJM 2007; 100: 317-334.

3 Rankin NE. Disseminated aspergillosis and moniliasis associated with agranulocytosis and antibiotic therapy. Br Med J 1953; 1: 918-919.

4 McNeil MM, Nash SL, Hajjeh RA, Phelan MA, et al. Trends in mortality due to invasive mycotic diseases in the United States, 1980-1997. Clin Infect Dis 2001; 33: 641-647.

5 Chamilos G, Luna M, Lewis RE, et al. Invasive fungal infections in patients with hematologic malignancies in a tertiary care cancer center: an autopsy study over a 15-year period (19892003). Haematologica 2006; 91: 986-989.

6 Groll AH, Shah PM, Mentzel C, et al. Trends in the postmortem epidemiology of invasive fungal infections at a university hospital. J Infect 1996; 33: 23-32.

7 Yeghen T, Kibbler CC, Prentice HG, et al. Management of invasive pulmonary aspergillosis in hematology patients: a review of 87 consecutive cases at a single institution. Clin Infect Dis 2000; 31: 859-868.

8 Fukuda T, Boeckh M, Carter RA, et al. Risks and outcomes of invasive fungal infections in recipients of allogeneic hematopoietic stem cell transplants after nonmyeloablative conditioning. Blood 2003; 102: 827-833.

9 Schaffner A, Douglas H, Braude A. Selective protection against conidia by mononuclear and against mycelia by polymorphonuclear phagocytes in resistance to Aspergillus. Observations on these two lines of defense in vivo and in vitro with human and mouse phagocytes. J Clin Invest 1982; 69: 617-631.

10 Gerson SL, Talbot GH, Hurwitz S, et al. Prolonged granulocytopenia: the major risk factor for invasive pulmonary aspergillosis in patients with acute leukemia. Ann Intern Med 1984; 100: 345-351.

11 Kotloff RM, Ahya VN, Crawford SW. Pulmonary complications of solid organ and hematopoietic stem cell transplantation. Am J Respir Crit Care Med 2004; 170: 22-48.

12 Morgan J, Wannemuehler KA, Marr KA, et al. Incidence of invasive aspergillosis following hematopoietic stem cell and solid organ transplantation: interim results of a prospective multicenter surveillance program. Med Mycol 2005; 43: Suppl. 1, S49-S58.

13 Wald A, Leisenring W, van Burik JA, et al. Epidemiology of Aspergillus infections in a large cohort of patients undergoing bone marrow transplantation. J Infect Dis 1997; 175: 1459-1466. 
14 Marr KA, Carter RA, Boeckh M, et al. Invasive aspergillosis in allogeneic stem cell transplant recipients: changes in epidemiology and risk factors. Blood 2002; 100: 4358-4366.

15 Segal BH, Walsh TJ. Current approaches to diagnosis and treatment of invasive aspergillosis. Am J Respir Crit Care Med 2006; 173: 707-717.

16 Lionakis MS, Kontoyiannis DP. Glucocorticoids and invasive fungal infections. Lancet 2003; 362: 1828-1838.

17 Warris A, Bjorneklett A, Gaustad P. Invasive pulmonary aspergillosis associated with infliximab therapy. $N$ Engl J Med 2001; 344: 1099-1100.

18 Holding KJ, Dworkin MS, Wan PC, et al. Aspergillosis among people infected with human immunodeficiency virus: incidence and survival. Adult and adolescent spectrum of HIV disease project. Clin Infect Dis 2000; 31: 1253-1257.

19 Denning DW, Follansbee SE, Scolaro M, et al. Pulmonary aspergillosis in the acquired immunodeficiency syndrome. $N$ Engl J Med 1991; 324: 654-662.

20 Lortholary O, Meyohas MC, Dupont B, et al. Invasive aspergillosis in patients with acquired immunodeficiency syndrome: report of 33 cases. French cooperative study group on aspergillosis in AIDS. Am J Med 1993; 95: 177-187.

21 Mylonakis E, Barlam TF, Flanigan T, et al. Pulmonary aspergillosis and invasive disease in AIDS: review of 342 cases. Chest 1998; 114: 251-262.

22 Segal BH, Barnhart LA, Anderson VL, et al. Posaconazole as salvage therapy in patients with chronic granulomatous disease and invasive filamentous fungal infection. Clin Infect Dis 2005; 40: $1684-1688$.

23 Soubani AO, Miller KB, Hassoun PM. Pulmonary complications of bone marrow transplantation. Chest 1996; 109: 1066-1077.

24 Marr KA, Carter RA, Crippa F, et al. Epidemiology and outcome of mould infections in hematopoietic stem cell transplant recipients. Clin Infect Dis 2002; 34: 909-917.

25 Baddley JW, Stroud TP, Salzman D, et al. Invasive mold infections in allogeneic bone marrow transplant recipients. Clin Infect Dis 2001; 32: 1319-1324.

26 Junghanss C, Marr KA, Carter RA, et al. Incidence and outcome of bacterial and fungal infections following nonmyeloablative compared with myeloablative allogeneic hematopoietic stem cell transplantation: a matched control study. Biol Blood Marrow Transplant 2002; 8: 512-520.

27 Cordonnier C, Ribaud P, Herbrecht R, et al. Prognostic factors for death due to invasive aspergillosis after hematopoietic stem cell transplantation: a 1-year retrospective study of consecutive patients at French transplantation centers. Clin Infect Dis 2006; 42: 955-963.

28 Ribaud P, Chastang C, Latge JP, et al. Survival and prognostic factors of invasive aspergillosis after allogeneic bone marrow transplantation. Clin Infect Dis 1999; 28: 322-330.

29 van Burik JA, Carter SL, Freifeld AG, et al. Higher risk of cytomegalovirus and Aspergillus infections in recipients of $\mathrm{T}$ cell-depleted unrelated bone marrow: analysis of infectious complications in patients treated with $\mathrm{T}$ cell depletion versus immunosuppressive therapy to prevent graft-versus-host disease. Biol Blood Marrow Transplant 2007; 13: 1487-1498.

30 Nichols WG, Corey L, Gooley T, et al. High risk of death due to bacterial and fungal infection among cytomegalovirus (CMV)seronegative recipients of stem cell transplants from seropositive donors: evidence for indirect effects of primary CMV infection. I Infect Dis 2002; 185: 273-282.

31 Kemper CA, Hostetler JS, Follansbee SE, et al. Ulcerative and plaque-like tracheobronchitis due to infection with Aspergillus in patients with AIDS. Clin Infect Dis 1993; 17: 344-352.

32 Wallace JM, Lim R, Browdy BL, et al. Risk factors and outcomes associated with identification of Aspergillus in respiratory specimens from persons with HIV disease. Pulmonary complications of HIV infection study group. Chest 1998; 114: 131-137.

33 Libanore M, Prini E, Mazzetti M, et al. Invasive aspergillosis in Italian AIDS patients. Infection 2002; 30: 341-345.

34 Hawgood S, Ochs M, Jung A, et al. Sequential targeted deficiency of SP-A and -D leads to progressive alveolar lipoproteinosis and emphysema. Am J Physiol Lung Cell Mol Physiol 2002; 283: L1002-L1010.

35 Clark H, Reid K. The potential of recombinant surfactant protein $\mathrm{D}$ therapy to reduce inflammation in neonatal chronic lung disease, cystic fibrosis, and emphysema. Arch Dis Child 2003; 88: 981-984.

36 Wert SE, Yoshida M, LeVine AM, et al. Increased metalloproteinase activity, oxidant production, and emphysema in surfactant protein D gene-inactivated mice. Proc Natl Acad Sci USA 2000; 97: 5972-5977.

37 Bochud PY, Chien JW, Marr KA, et al. Toll-like receptor 4 polymorphisms and aspergillosis in stem-cell transplantation. N Engl J Med 2008; 359: 1766-1777.

38 Sarir H, Mortaz E, Karimi K, et al. Cigarette smoke regulates the expression of TLR4 and IL-8 production by human macrophages. J Inflamm (Lond) 2009; 6: 12.

39 Soubani AO, Khanchandani G, Ahmed HP. Clinical significance of lower respiratory tract aspergillus culture in elderly hospitalized patients. Eur J Clin Microbiol Infect Dis 2004; 23: 491-494.

40 Samarakoon $\mathrm{P}$, Soubani AO. Invasive pulmonary aspergillosis in patients with COPD, a report of five cases and systematic review of the literature. Chron Respir Dis 2008; 5: 19-27.

41 Ader F, Nseir S, Le Berre R, et al. Invasive pulmonary aspergillosis in chronic obstructive pulmonary disease: an emerging fungal pathogen. Clin Microbiol Infect 2005; 11: 427-429.

42 Carrascosa Porras M, Herreras Martinez R, Corral Mones J, et al. Fatal Aspergillus myocarditis following short-term corticosteroid therapy for chronic obstructive pulmonary disease. Scand J Infect Dis 2002; 34: 224-227.

43 Bulpa PA, Dive AM, Garrino MG, et al. Chronic obstructive pulmonary disease patients with invasive pulmonary aspergillosis: benefits of intensive care? Intensive Care Med 2001; 27: 59-67.

44 Vandewoude $\mathrm{KH}$, Blot SI, Depuydt P, et al. Clinical relevance of Aspergillus isolation from respiratory tract samples in critically ill patients. Crit Care 2006; 10: R31.

45 Dimopoulos G, Piagnerelli M, Berre J, et al. Disseminated aspergillosis in intensive care unit patients: an autopsy study. J Chemother 2003; 15: 71-75.

46 Vandewoude $\mathrm{KH}$, Blot SI, Benoit D, et al. Invasive aspergillosis in critically ill patients: attributable mortality and excesses in length of ICU stay and ventilator dependence. J Hosp Infect 2004; 56: 269-276.

47 Meersseman W, Vandecasteele SJ, Wilmer A, et al. Invasive aspergillosis in critically ill patients without malignancy. $A m \mathrm{~J}$ Respir Crit Care Med 2004; 170: 621-625.

48 Janssen JJ, Strack van Schijndel RJ, van der Poest Clement EH, et al. Outcome of ICU treatment in invasive aspergillosis. Intensive Care Med 1996; 22: 1315-1322.

49 Meersseman W, Lagrou K, Maertens J, et al. Invasive aspergillosis in the intensive care unit. Clin Infect Dis 2007; 45: 205-216.

50 Garnacho-Montero J, Amaya-Villar R, Ortiz-Leyba C, et al. Isolation of Aspergillus spp. from the respiratory tract in critically ill patients: risk factors, clinical presentation and outcome. Crit Care 2005; 9: R191-R199.

51 Garnacho-Montero J, Amaya-Villar R. A validated clinical approach for the management of aspergillosis in critically ill patients: Ready, steady, go! Crit Care 2006; 10: 132.

52 Khasawneh F, Mohamad T, Moughrabieh MK, et al. Isolation of Aspergillus in critically ill patients: a potential marker of poor outcome. J Crit Care 2006; 21: 322-327. 
53 Iwen PC, Rupp ME, Langnas AN, et al. Invasive pulmonary aspergillosis due to Aspergillus terreus: 12-year experience and review of the literature. Clin Infect Dis 1998; 26: 1092-1097.

54 Young RC, Bennett JE, Vogel CL, et al. Aspergillosis. The spectrum of the disease in 98 patients. Medicine (Baltimore) 1970; 49: 147-173.

55 Prystowsky SD, Vogelstein B, Ettinger DS, et al. Invasive aspergillosis. N Engl J Med 1976; 295: 655-658.

56 Allo MD, Miller J, Townsend T, et al. Primary cutaneous aspergillosis associated with Hickman intravenous catheters. N Engl J Med 1987; 317: 1105-1108.

57 Albelda SM, Talbot GH, Gerson SL, et al. Pulmonary cavitation and massive hemoptysis in invasive pulmonary aspergillosis. Influence of bone marrow recovery in patients with acute leukemia. Am Rev Respir Dis 1985; 131: 115-120.

58 Denning DW. Invasive aspergillosis. Clin Infect Dis 1998; 26: 781-803.

59 Judson MA, Sahn SA. Endobronchial lesions in HIV-infected individuals. Chest 1994; 105: 1314-1323.

60 Nathan SD, Shorr AF, Schmidt ME, et al. Aspergillus and endobronchial abnormalities in lung transplant recipients. Chest 2000; 118: 403-407.

$61 \mathrm{Wu} \mathrm{N}$, Huang $\mathrm{Y}, \mathrm{Li} \mathrm{Q}$, et al. Isolated invasive Aspergillus tracheobronchitis: a clinical study of 19 cases. Clin Microbiol Infect 2010; 16: 689-695.

62 Denning DW. Commentary: unusual manifestations of aspergillosis. Thorax 1995; 50: 812-813.

63 Tasci S, Glasmacher A, Lentini S, et al. Pseudomembranous and obstructive Aspergillus tracheobronchitis - optimal diagnostic strategy and outcome. Mycoses 2006; 49: 37-42.

64 Ruhnke M, Bohme A, Buchheidt D, et al. Diagnosis of invasive fungal infections in hematology and oncology-guidelines of the infectious diseases working party (AGIHO) of the German society of Hematology and Oncology (DGHO). Ann Hematol 2003; 82: Suppl. 2, S141-S148.

65 Nalesnik MA, Myerowitz RL, Jenkins R, et al. Significance of Aspergillus species isolated from respiratory secretions in the diagnosis of invasive pulmonary aspergillosis. J Clin Microbiol 1980; 11: 370-376.

66 Horvath JA, Dummer S. The use of respiratory-tract cultures in the diagnosis of invasive pulmonary aspergillosis. Am J Med 1996; 100: 171-178.

67 Treger TR, Visscher DW, Bartlett MS, et al. Diagnosis of pulmonary infection caused by Aspergillus: usefulness of respiratory cultures. J Infect Dis 1985; 152: 572-576.

68 Soubani AO, Qureshi MA. Invasive pulmonary aspergillosis following bone marrow transplantation: risk factors and diagnostic aspect. Haematologia (Budap) 2002; 32: 427-437.

$69 \mathrm{Yu} \mathrm{VL}$, Muder RR, Poorsattar A. Significance of isolation of Aspergillus from the respiratory tract in diagnosis of invasive pulmonary aspergillosis. Results from a three-year prospective study. Am J Med 1986; 81: 249-254.

70 Tang CM, Cohen J. Diagnosing fungal infections in immunocompromised hosts. J Clin Pathol 1992; 45: 1-5.

71 Duthie R, Denning DW. Aspergillus fungemia: report of two cases and review. Clin Infect Dis 1995; 20: 598-605.

72 Libshitz HI, Pagani JJ. Aspergillosis and mucormycosis: two types of opportunistic fungal pneumonia. Radiology 1981; 140: 301-306.

73 Kuhlman JE, Fishman EK, Siegelman SS. Invasive pulmonary aspergillosis in acute leukemia: characteristic findings on $\mathrm{CT}$, the CT halo sign, and the role of CT in early diagnosis. Radiology 1985; 157: 611-614

74 Caillot D, Casasnovas O, Bernard A, et al. Improved management of invasive pulmonary aspergillosis in neutropenic patients using early thoracic computed tomographic scan and surgery. J Clin Oncol 1997; 15: 139-147.
75 Caillot D, Mannone L, Cuisenier B, et al. Role of early diagnosis and aggressive surgery in the management of invasive pulmonary aspergillosis in neutropenic patients. Clin Microbiol Infect 2001; 7: Suppl. 2, 54-61.

76 Kuhlman JE, Fishman EK, Burch PA, et al. Invasive pulmonary aspergillosis in acute leukemia. The contribution of CT to early diagnosis and aggressive management. Chest 1987; 92: 95-99.

77 Curtis AM, Smith GJ, Ravin CE. Air crescent sign of invasive aspergillosis. Radiology 1979; 133: 17-21.

78 Gaeta M, Blandino A, Scribano E, et al. Computed tomography halo sign in pulmonary nodules: frequency and diagnostic value. J Thorac Imaging 1999; 14: 109-113.

79 Greene R. The radiological spectrum of pulmonary aspergillosis. Med Mycol 2005; 43: Suppl. 1, S147-S154.

80 Heussel CP, Kauczor HU, Heussel GE, et al. Pneumonia in febrile neutropenic patients and in bone marrow and blood stem-cell transplant recipients: use of high-resolution computed tomography. J Clin Oncol 1999; 17: 796-805.

81 Horger M, Hebart $H$, Einsele $H$, et al. Initial CT manifestations of invasive pulmonary aspergillosis in 45 non-HIV immunocompromised patients: association with patient outcome? Eur J Radiol 2005; 55: 437-444.

82 Albelda SM, Talbot GH, Gerson SL, et al. Role of fiberoptic bronchoscopy in the diagnosis of invasive pulmonary aspergillosis in patients with acute leukemia. Am J Med 1984; 76: 1027-1034.

83 Kahn FW, Jones JM, England DM. The role of bronchoalveolar lavage in the diagnosis of invasive pulmonary aspergillosis. Am J Clin Pathol 1986; 86: 518-523.

84 Levy H, Horak DA, Tegtmeier BR, et al. The value of bronchoalveolar lavage and bronchial washings in the diagnosis of invasive pulmonary aspergillosis. Respir Med 1992; 86: 243-248.

85 Reichenberger F, Habicht J, Matt P, et al. Diagnostic yield of bronchoscopy in histologically proven invasive pulmonary aspergillosis. Bone Marrow Transplant 1999; 24: 1195-1199.

86 Maschmeyer G, Beinert T, Buchheidt D, et al. Diagnosis and antimicrobial therapy of pulmonary infiltrates in febrile neutropenic patients-guidelines of the infectious diseases working party (AGIHO) of the German Society of Hematology and Oncology (DGHO). Ann Hematol 2003; 82: Suppl. 2, S118-S126.

87 Panackal AA, Marr KA. Scedosporium/Pseudallescheria infections. Semin Respir Crit Care Med 2004; 25: 171-181.

88 Walsh TJ, Groll AH. Overview: Non-fumigatus species of Aspergillus: perspectives on emerging pathogens in immunocompromised hosts. Curr Opin Investig Drugs 2001; 2: 1366-1367.

89 Lass-Florl C, Griff K, Mayr A, et al. Epidemiology and outcome of infections due to Aspergillus terreus: 10-year single centre experience. Br J Haematol 2005; 131: 201-207.

90 Steinbach WJ, Benjamin DK Jr, Kontoyiannis DP, et al. Infections due to Aspergillus terreus: a multicenter retrospective analysis of 83 cases. Clin Infect Dis 2004; 39: 192-198.

91 Hachem RY, Kontoyiannis DP, Boktour MR, et al. Aspergillus terreus: an emerging amphotericin B-resistant opportunistic mold in patients with hematologic malignancies. Cancer 2004; 101: 1594-1600.

92 Kontoyiannis DP, Lewis RE, May GS, et al. Aspergillus nidulans is frequently resistant to amphotericin B. Mycoses 2002; 45: 406-407.

93 Walsh TJ, Raad I, Patterson TF, et al. Treatment of invasive aspergillosis with posaconazole in patients who are refractory to or intolerant of conventional therapy: an externally controlled trial. Clin Infect Dis 2007; 44: 2-12.

94 Boutboul F, Alberti C, Leblanc T, et al. Invasive aspergillosis in allogeneic stem cell transplant recipients: increasing antigenemia is associated with progressive disease. Clin Infect Dis 2002; 34: 939-943.

95 Marr KA, Balajee SA, McLaughlin L, et al. Detection of galactomannan antigenemia by enzyme immunoassay for the 
diagnosis of invasive aspergillosis: variables that affect performance. J Infect Dis 2004; 190: 641-649.

96 Pfeiffer CD, Fine JP, Safdar N. Diagnosis of invasive aspergillosis using a galactomannan assay: a meta-analysis. Clin Infect Dis 2006; 42: 1417-1427.

97 Ascioglu S, Rex JH, de Pauw B, et al. Defining opportunistic invasive fungal infections in immunocompromised patients with cancer and hematopoietic stem cell transplants: an international consensus. Clin Infect Dis 2002; 34: 7-14.

98 Herbrecht R, Letscher-Bru V, Oprea C, et al. Aspergillus galactomannan detection in the diagnosis of invasive aspergillosis in cancer patients. J Clin Oncol 2002; 20: 1898-1906.

99 Singh N, Obman A, Husain S, et al. Reactivity of platelia Aspergillus galactomannan antigen with piperacillin-tazobactam: clinical implications based on achievable concentrations in serum. Antimicrob Agents Chemother 2004; 48: 1989-1992.

100 Marr KA, Laverdiere M, Gugel A, et al. Antifungal therapy decreases sensitivity of the Aspergillus galactomannan enzyme immunoassay. Clin Infect Dis 2005; 40: 1762-1769.

101 Ansorg R, van den Boom R, Rath PM. Detection of Aspergillus galactomannan antigen in foods and antibiotics. Mycoses 1997; 40: 353-357.

102 Busca A, Locatelli F, Barbui A, et al. Usefulness of sequential Aspergillus galactomannan antigen detection combined with early radiologic evaluation for diagnosis of invasive pulmonary aspergillosis in patients undergoing allogeneic stem cell transplantation. Transplant Proc 2006; 38: 1610-1613.

103 Musher B, Fredricks D, Leisenring W, et al. Aspergillus galactomannan enzyme immunoassay and quantitative PCR for diagnosis of invasive aspergillosis with bronchoalveolar lavage fluid. J Clin Microbiol 2004; 42: 5517-5522.

104 Klont RR, Mennink-Kersten MA, Verweij PE. Utility of Aspergillus antigen detection in specimens other than serum specimens. Clin Infect Dis 2004; 39: 1467-1474.

105 Salonen J, Lehtonen OP, Terasjarvi MR, et al. Aspergillus antigen in serum, urine and bronchoalveolar lavage specimens of neutropenic patients in relation to clinical outcome. Scand J Infect Dis 2000; 32: 485-490.

106 Danpornprasert P, Foongladda S, Tscheikuna J. Impact of bronchoalveolar lavage galactomannan on the outcome of patients at risk for invasive pulmonary aspergillosis. J Med Assoc Thai 2010; 93: Suppl. 1, S86-S93.

107 Hsu LY, Ding Y, Phua J, et al. Galactomannan testing of bronchoalveolar lavage fluid is useful for diagnosis of invasive pulmonary aspergillosis in hematology patients. BMC Infect Dis 2010; 10: 44.

108 Meersseman W, Lagrou K, Maertens J, et al. Galactomannan in bronchoalveolar lavage fluid: a tool for diagnosing aspergillosis in intensive care unit patients. Am J Respir Crit Care Med 2008; 177: $27-34$.

109 Clancy CJ, Jaber RA, Leather HL, et al. Bronchoalveolar lavage galactomannan in diagnosis of invasive pulmonary aspergillosis among solid-organ transplant recipients. J Clin Microbiol 2007; 45 1759-1765.

110 Viscoli C, Machetti M, Gazzola P, et al. Aspergillus galactomannan antigen in the cerebrospinal fluid of bone marrow transplant recipients with probable cerebral aspergillosis. J Clin Microbiol 2002; 40: 1496-1499.

111 Hizel K, Kokturk N, Kalkanci A, et al. Polymerase chain reaction in the diagnosis of invasive aspergillosis. Mycoses 2004; 47: 338-342.

112 Buchheidt D, Baust C, Skladny H, et al. Detection of Aspergillus species in blood and bronchoalveolar lavage samples from immunocompromised patients by means of 2-step polymerase chain reaction: clinical results. Clin Infect Dis 2001; 33: 428-435.

113 Loeffler J, Kloepfer K, Hebart H, et al. Polymerase chain reaction detection of Aspergillus DNA in experimental models of invasive aspergillosis. J Infect Dis 2002; 185: 1203-1206.
114 Halliday C, Hoile R, Sorrell T, et al. Role of prospective screening of blood for invasive aspergillosis by polymerase chain reaction in febrile neutropenic recipients of haematopoietic stem cell transplants and patients with acute leukaemia. Br J Haematol 2006; 132: 478-486

115 Obayashi T, Yoshida M, Mori T, et al. Plasma (1->3)-beta-Dglucan measurement in diagnosis of invasive deep mycosis and fungal febrile episodes. Lancet 1995; 345: 17-20.

116 Pazos C, Ponton J, Del Palacio A. Contribution of (1->3)-beta-Dglucan chromogenic assay to diagnosis and therapeutic monitoring of invasive aspergillosis in neutropenic adult patients: a comparison with serial screening for circulating galactomannan. J Clin Microbiol 2005; 43: 299-305.

117 De Pauw B, Walsh TJ, Donnelly JP, et al. Revised definitions of invasive fungal disease from the European Organization for Research and Treatment of Cancer/invasive fungal infections cooperative group and the National Institute of Allergy and Infectious Diseases mycoses study group (EORTC/MSG) consensus group. Clin Infect Dis 2008; 46: 1813-1821.

118 de Pauw BE, Patterson TF. Should the consensus guidelines' specific criteria for the diagnosis of invasive fungal infection be changed? Clin Infect Dis 2005; 41: Suppl. 6, S377-S380.

119 Johnson LB, Kauffman CA. Voriconazole: a new triazole antifungal agent. Clin Infect Dis 2003; 36: 630-637.

120 Sambatakou H, Dupont B, Lode H, et al. Voriconazole treatment for subacute invasive and chronic pulmonary aspergillosis. Am J Med 2006; 119: 527 e517-524.

121 Ghannoum MA, Kuhn DM. Voriconazole - better chances for patients with invasive mycoses. Eur J Med Res 2002; 7: 242-256.

122 Herbrecht R, Denning DW, Patterson TF, et al. Voriconazole versus amphotericin B for primary therapy of invasive aspergillosis. N Engl J Med 2002; 347: 408-415.

123 Limper AH, Knox KS, Sarosi GA, et al. An official American Thoracic Society statement: treatment of fungal infections in adult pulmonary and critical care patients. Am J Respir Crit Care Med 2011; 183: 96-128.

124 Cornely OA, Maertens J, Bresnik M, et al. Liposomal amphotericin B as initial therapy for invasive mold infection: a randomized trial comparing a high-loading dose regimen with standard dosing (AmBiLoad trial). Clin Infect Dis 2007; 44: 1289-1297.

125 Pitisuttithum P, Negroni R, Graybill JR, et al. Activity of posaconazole in the treatment of central nervous system fungal infections. J Antimicrob Chemother 2005; 56: 745-755.

126 Spanakis EK, Aperis G, Mylonakis E et al. New agents for the treatment of fungal infections: clinical efficacy and gaps in coverage. Clin Infect Dis 2006; 43: 1060-1068.

127 Cohen-Wolkowiez M, Benjamin DK Jr, Steinbach WJ, et al. Anidulafungin: a new echinocandin for the treatment of fungal infections. Drugs Today (Barc) 2006; 42: 533-544.

128 Saraceno JL, Phelps DT, Ferro TJ, et al. Chronic necrotizing pulmonary aspergillosis: approach to management. Chest 1997; 112: 541-548.

129 Caras WE, Pluss JL. Chronic necrotizing pulmonary aspergillosis: pathologic outcome after itraconazole therapy. Mayo Clin Proc 1996; 71: 25-30.

130 Binder RE, Faling LJ, Pugatch RD, et al. Chronic necrotizing pulmonary aspergillosis: a discrete clinical entity. Medicine (Baltimore) 1982; 61: 109-124.

131 Uflacker R, Kaemmerer A, Picon PD, et al. Bronchial artery embolization in the management of hemoptysis: technical aspects and long-term results. Radiology 1985; 157: 637-644.

132 Soltanzadeh H, Wychulis AR, Sadr F, et al. Surgical treatment of pulmonary aspergilloma. Ann Surg 1977; 186: 13-16.

133 Massard G, Roeslin N, Wihlm JM, et al. Pleuropulmonary aspergilloma: clinical spectrum and results of surgical treatment. Ann Thorac Surg 1992; 54: 1159-1164. 
134 Kilman JW, Ahn C, Andrews NC, et al. Surgery for pulmonary aspergillosis. J Thorac Cardiovasc Surg 1969; 57: 642-647.

135 Chen JC, Chang YL, Luh SP, et al. Surgical treatment for pulmonary aspergilloma: a 28 year experience. Thorax 1997; 52: 810-813.

136 Campbell JH, Winter JH, Richardson MD, et al. Treatment of pulmonary aspergilloma with itraconazole. Thorax 1991; 46: 839-841.

137 Dupont B. Itraconazole therapy in aspergillosis: study in 49 patients. J Am Acad Dermatol 1990; 23: 607-614.

138 Impens N, De Greve J, De Beule K, et al. Oral treatment with itraconazole of aspergilloma in cavitary lung cancer. Eur Respir J 1990; 3: 837-839.

139 Rosenberg M, Patterson R, Roberts $M$, et al. The assessment of immunologic and clinical changes occurring during corticosteroid therapy for allergic bronchopulmonary aspergillosis. Am J Med 1978; 64: 599-606.

140 Wang JL, Patterson R, Roberts $\mathrm{M}$, et al. The management of allergic bronchopulmonary aspergillosis. Am Rev Respir Dis 1979; 120: 87-92.

141 Capewell S, Chapman BJ, Alexander F, et al. Corticosteroid treatment and prognosis in pulmonary eosinophilia. Thorax 1989; 44: 925-929.

142 Safirstein BH, D'Souza MF, Simon G, et al. Five-year follow-up of allergic bronchopulmonary aspergillosis. Am Rev Respir Dis 1973; 108: 450-459.

143 Stevens DA, Schwartz HJ, Lee JY, et al. A randomized trial of itraconazole in allergic bronchopulmonary aspergillosis. $\mathrm{N} \mathrm{Engl} \mathrm{J}$ Med 2000; 342: 756-762.

144 Mulliez P, Croxo C, Roy-Saint Georges F, et al. Allergic bronchopulmonary aspergillosis treated with voriconazole. Rev Mal Respir 2006; 23: 93-94.

145 Bandres Gimeno R, Munoz Martinez MJ. Prolonged therapeutic response to voriconazole in a case of allergic bronchopulmonary aspergillosis. Arch Bronconeumol 2007; 43: 49-51.

146 Erwin GE, Fitzgerald JE. Case report: allergic bronchopulmonary aspergillosis and allergic fungal sinusitis successfully treated with voriconazole. J Asthma 2007; 44: 891-895.

147 Pascual A, Calandra T, Bolay S, et al. Voriconazole therapeutic drug monitoring in patients with invasive mycoses improves efficacy and safety outcomes. Clin Infect Dis 2008; 46: 201-211.

148 Aliff TB, Maslak PG, Jurcic JG, et al. Refractory Aspergillus pneumonia in patients with acute leukemia: successful therapy with combination caspofungin and liposomal amphotericin. Cancer 2003; 97: 1025-1032.

149 Kontoyiannis DP, Hachem R, Lewis RE, et al. Efficacy and toxicity of caspofungin in combination with liposomal amphotericin B as primary or salvage treatment of invasive aspergillosis in patients with hematologic malignancies. Cancer 2003; 98 : 292-299.

150 Graybill JR, Bocanegra R, Gonzalez GM, et al. Combination antifungal therapy of murine aspergillosis: liposomal amphotericin B and micafungin. J Antimicrob Chemother 2003; 52: 656-662.

151 Marr KA, Boeckh M, Carter RA, et al. Combination antifungal therapy for invasive aspergillosis. Clin Infect Dis 2004; 39: 797-802.

152 Perea S, Gonzalez G, Fothergill AW, et al. In vitro interaction of caspofungin acetate with voriconazole against clinical isolates of Aspergillus spp. Antimicrob Agents Chemother 2002; 46: 3039-3041.

153 Singh N, Limaye AP, Forrest G, et al. Combination of voriconazole and caspofungin as primary therapy for invasive aspergillosis in solid organ transplant recipients: a prospective, multicenter, observational study. Transplantation 2006; 81: 320-326.

154 Denning DW, Marr KA, Lau WM, et al. Micafungin (fk463), alone or in combination with other systemic antifungal agents, for the treatment of acute invasive aspergillosis. J Infect 2006; 53: 337-349.
155 Fluckiger U, Marchetti O, Bille J, et al. Treatment options of invasive fungal infections in adults. Swiss Med Wkly 2006; 136: 447-463.

156 Klont RR, Mennink-Kersten MA, Ruegebrink D, et al. Paradoxical increase in circulating Aspergillus antigen during treatment with caspofungin in a patient with pulmonary aspergillosis. Clin Infect Dis 2006; 43: e23-e25.

157 Moreau P, Zahar JR, Milpied N, et al. Localized invasive pulmonary aspergillosis in patients with neutropenia. Effectiveness of surgical resection. Cancer 1993; 72: 3223-3226.

158 Reichenberger F, Habicht J, Kaim A, et al. Lung resection for invasive pulmonary aspergillosis in neutropenic patients with hematologic diseases. Am J Respir Crit Care Med 1998; 158: 885-890.

159 Habicht JM, Reichenberger F, Gratwohl A, et al. Surgical aspects of resection for suspected invasive pulmonary fungal infection in neutropenic patients. Ann Thorac Surg 1999; 68: 321-325.

160 Pidhorecky I, Urschel J, Anderson T. Resection of invasive pulmonary aspergillosis in immunocompromised patients. Ann Surg Oncol 2000; 7: 312-317.

161 Matt $\mathrm{P}$, Bernet F, Habicht J, et al. Predicting outcome after lung resection for invasive pulmonary aspergillosis in patients with neutropenia. Chest 2004; 126: 1783-1788.

162 Baron O, Guillaume B, Moreau P, et al. Aggressive surgical management in localized pulmonary mycotic and nonmycotic infections for neutropenic patients with acute leukemia: report of eighteen cases. J Thorac Cardiovasc Surg 1998; 115: 63-68.

163 Giles FJ. Monocyte-macrophages, granulocyte-macrophage colonystimulating factor, and prolonged survival among patients with acute myeloid leukemia and stem cell transplants. Clin Infect Dis 1998; 26: 1282-1289.

164 Roilides E, Holmes A, Blake C, et al. Antifungal activity of elutriated human monocytes against Aspergillus fumigatus hyphae: enhancement by granulocyte-macrophage colonystimulating factor and interferon- $\gamma$. J Infect Dis 1994; 170: 894-899.

165 Roilides E, Sein T, Holmes A, et al. Effects of macrophage colonystimulating factor on antifungal activity of mononuclear phagocytes against Aspergillus fumigatus. J Infect Dis 1995; 172: 1028-1034.

166 Rowe JM, Andersen JW, Mazza JJ, et al. A randomized placebocontrolled phase III study of granulocyte-macrophage colonystimulating factor in adult patients ( $>55$ to 70 years of age) with acute myelogenous leukemia: a study of the eastern cooperative oncology group (e1490). Blood 1995; 86: 457-462.

167 Ozer H, Armitage JO, Bennett CL, et al. 2000 update of recommendations for the use of hematopoietic colony-stimulating factors: evidence-based, clinical practice guidelines. American Society of Clinical Oncology growth factors expert panel. J Clin Oncol 2000; 18: 3558-3585.

168 Roilides E, Uhlig K, Venzon D, et al. Prevention of corticosteroidinduced suppression of human polymorphonuclear leukocyteinduced damage of Aspergillus fumigatus hyphae by granulocyte colony-stimulating factor and gamma interferon. Infect Immun 1993; 61: 4870-4877.

169 Nagai $\mathrm{H}$, Guo J, Choi $\mathrm{H}$, et al. Interferon- $\gamma$ and tumour necrosis factor- $\alpha$ protect mice from invasive aspergillosis. J Infect Dis 1995; 172: $1554-1560$

170 A controlled trial of interferon gamma to prevent infection in chronic granulomatous disease. The international chronic granulomatous disease cooperative study group. N Engl J Med 1991; 324: 509-516.

171 Safdar A. Strategies to enhance immune function in hematopoietic transplantation recipients who have fungal infections. Bone Marrow Transplant 2006; 38: 327-337.

172 Safdar A, Rodriguez G, Ohmagari N, et al. The safety of interferon- $\gamma-1 b$ therapy for invasive fungal infections after hematopoietic stem cell transplantation. Cancer 2005; 103: 731-739. 
173 Price TH, Bowden RA, Boeckh $\mathrm{M}$, et al. Phase I/II trial of neutrophil transfusions from donors stimulated with G-CSF and dexamethasone for treatment of patients with infections in hematopoietic stem cell transplantation. Blood 2000; 95: 3302-3309.

174 Sherertz RJ, Belani A, Kramer BS, et al. Impact of air filtration on nosocomial aspergillus infections. Unique risk of bone marrow transplant recipients. Am J Med 1987; 83: 709-718.

175 Mattiuzzi GN, Kantariian $\mathrm{H}, \mathrm{O}^{\prime}$ Brien $\mathrm{S}$, et al. Intravenous itraconazole for prophylaxis of systemic fungal infections in patients with acute myelogenous leukemia and high-risk myelodysplastic syndrome undergoing induction chemotherapy. Cancer 2004; 100: 568-573.

176 Ullmann AJ, Cornely OA. Antifungal prophylaxis for invasive mycoses in high risk patients. Curr Opin Infect Dis 2006; 19 571-576.

177 Ullmann AJ, Lipton $\mathrm{JH}$, Vesole $\mathrm{DH}$, et al. Posaconazole or fluconazole for prophylaxis in severe graft-versus-host disease. N Engl J Med 2007; 356: 335-347.

178 Cornely OA, Maertens J, Winston DJ, et al. Posaconazole vs. fluconazole or itraconazole prophylaxis in patients with neutropenia. N Engl J Med 2007; 356: 348-359.

179 Gefter WB, Weingrad TR, Epstein DM, et al. "Semi-invasive" pulmonary aspergillosis: a new look at the spectrum of aspergillus infections of the lung. Radiology 1981; 140: 313-321.

180 Grahame-Clarke CN, Roberts CM, Empey DW. Chronic necrotizing pulmonary aspergillosis and pulmonary phycomycosis in cystic fibrosis. Respir Med 1994; 88: 465-468.

181 Crosdale DJ, Poulton KV, Ollier WE, et al. Mannose-binding lectin gene polymorphisms as a susceptibility factor for chronic necrotizing pulmonary aspergillosis. I Infect Dis 2001; 184: 653-656.

182 Denning DW. Chronic forms of pulmonary aspergillosis. Clin Microbiol Infect 2001; 7: Suppl. 2, 25-31.

183 Soubani AO. Aspergillus overlap syndromes. In: Pasqualotto A, ed. Aspergillosis: from Diagnosis to Prevention. Dordrecht, Springer, 2010: pp. 817-831.

184 Kim SY, Lee KS, Han J, et al. Semiinvasive pulmonary aspergillosis: $\mathrm{CT}$ and pathologic findings in six patients. AJR Am J Roentgenol 2000; 174: 795-798.

185 Parra I, Remacha A, Rezusta A, et al. Chronic necrotizing pulmonary aspergillosis. Med Mycol 2004; 42: 369-371.

186 Denning DW, Riniotis K, Dobrashian R, et al. Chronic cavitary and fibrosing pulmonary and pleural aspergillosis: case series, proposed nomenclature change, and review. Clin Infect Dis 2003; 37: Suppl. 3, S265-S280.

187 Kauffman CA. Quandary about treatment of aspergillomas persists. Lancet 1996; 347: 1640.

188 Zizzo G, Castriota-Scanderbeg A, Zarrelli N, et al. Pulmonary aspergillosis complicating ankylosing spondylitis. Radiol Med 1996; 91: 817-818.

189 Kawamura S, Maesaki S, Tomono K, et al. Clinical evaluation of 61 patients with pulmonary aspergilloma. Intern Med 2000; 39: 209-212.

190 Aspergilloma and residual tuberculous cavities - the results of a resurvey. Tubercle 1970; 51: 227-245.

191 Rosenheim SH, Schwarz J. Cavitary pulmonary cryptococcosis complicated by aspergilloma. Am Rev Respir Dis 1975; 111: 549-553.

192 Sarosi GA, Silberfarb PM, Saliba NA, et al. Aspergillomas occurring in blastomycotic cavities. Am Rev Respir Dis 1971; 104: 581-584.

193 Tomee JF, van der Werf TS, Latge JP, et al. Serologic monitoring of disease and treatment in a patient with pulmonary aspergilloma. Am J Respir Crit Care Med 1995; 151: 199-204.

194 Rafferty P, Biggs BA, Crompton GK, et al. What happens to patients with pulmonary aspergilloma? Analysis of 23 cases. Thorax 1983; 38: 579-583.
195 Gefter WB. The spectrum of pulmonary aspergillosis. J Thorac Imaging 1992; 7: 56-74.

196 Faulkner SL, Vernon R, Brown PP, et al. Hemoptysis and pulmonary aspergilloma: operative versus nonoperative treatment. Ann Thorac Surg 1978; 25: 389-392.

197 Garvey J, Crastnopol P, Weisz D, et al. The surgical treatment of pulmonary aspergillomas. J Thorac Cardiovasc Surg 1977; 74: 542-547.

198 Daly RC, Pairolero PC, Piehler JM, et al. Pulmonary aspergilloma. Results of surgical treatment. J Thorac Cardiovasc Surg 1986; 92: 981-988.

199 Karas A, Hankins JR, Attar S, et al. Pulmonary aspergillosis: an analysis of 41 patients. Ann Thorac Surg 1976; 22: 1-7.

200 Jewkes J, Kay PH, Paneth M, et al. Pulmonary aspergilloma: analysis of prognosis in relation to haemoptysis and survey of treatment. Thorax 1983; 38: 572-578.

201 Glimp RA, Bayer AS. Pulmonary aspergilloma. Diagnostic and therapeutic considerations. Arch Intern Med 1983; 143: 303-308.

202 Addrizzo-Harris DJ, Harkin TJ, McGuinness G, et al. Pulmonary aspergilloma and AIDS. A comparison of HIV-infected and HIVnegative individuals. Chest 1997; 111: 612-618.

203 Aslam PA, Eastridge CE, Hughes FA Jr. Aspergillosis of the lung-an eighteen-year experience. Chest 1971; 59: 28-32.

204 Stevens DA, Kan VL, Judson MA, et al. Practice guidelines for diseases caused by Aspergillus. Infectious Diseases Society of America. Clin Infect Dis 2000; 30: 696-709.

205 Tuncel E. Pulmonary air meniscus sign. Respiration 1984; 46 139-144.

206 Roberts CM, Citron KM, Strickland B. Intrathoracic aspergilloma: role of CT in diagnosis and treatment. Radiology 1987; 165 : 123-128.

207 Bandoh S, Fujita J, Fukunaga Y, et al. Cavitary lung cancer with an aspergilloma-like shadow. Lung Cancer 1999; 26: 195-198.

208 Le Thi Huong D, Wechsler B, Chamuzeau JP, et al. Pulmonary aspergilloma complicating Wegener's granulomatosis. Scand J Rheumatol 1995; 24: 260.

209 McCarthy DS, Pepys J. Pulmonary aspergilloma-clinical immunology. Clin Allergy 1973; 3: 57-70.

210 Judson MA. Noninvasive Aspergillus pulmonary disease. Semin Respir Crit Care Med 2004; 25: 203-219.

211 Andrews CP, Weiner MH. Aspergillus antigen detection in bronchoalveolar lavage fluid from patients with invasive aspergillosis and aspergillomas. Am J Med 1982; 73: 372-380.

212 Yamada H, Kohno S, Koga $\mathrm{H}$, et al. Topical treatment of pulmonary aspergilloma by antifungals. Relationship between duration of the disease and efficacy of therapy. Chest 1993; 103: 1421-1425.

213 Munk PL, Vellet AD, Rankin RN, et al. Intracavitary aspergilloma: transthoracic percutaneous injection of amphotericin gelatin solution. Radiology 1993; 188: 821-823.

214 Lee KS, Kim HT, Kim YH, et al. Treatment of hemoptysis in patients with cavitary aspergilloma of the lung: value of percutaneous instillation of amphotericin B. AJR Am J Roentgenol 1993; 161: 727-731.

215 Klein JS, Fang K, Chang MC. Percutaneous transcatheter treatment of an intracavitary aspergilloma. Cardiovasc Intervent Radiol 1993; 16: 321-324.

216 Hammerman KJ, Sarosi GA, Tosh FE. Amphotericin B in the treatment of saprophytic forms of pulmonary aspergillosis. Am Rev Respir Dis 1974; 109: 57-62.

217 Tsubura E. Multicenter clinical trial of itraconazole in the treatment of pulmonary aspergilloma. Pulmonary aspergilloma study group. Kekkaku 1997; 72: 557-564

218 Patterson K, Strek ME. Allergic bronchopulmonary aspergillosis Proc Am Thorac Soc 2010; 7: 237-244.

219 Agarwal R. Allergic bronchopulmonary aspergillosis. Chest 2009; 135: 805-826. 
220 Stevens DA, Moss RB, Kurup VP, et al. Allergic bronchopulmonary aspergillosis in cystic fibrosis-state of the art: Cystic Fibrosis Foundation consensus conference. Clin Infect Dis 2003; 37: Suppl. 3, S225-S264.

221 Basich JE, Graves TS, Baz MN, et al. Allergic bronchopulmonary aspergillosis in corticosteroid-dependent asthmatics. J Allergy Clin Immunol 1981; 68: 98-102.

222 Mroueh S, Spock A. Allergic bronchopulmonary aspergillosis in patients with cystic fibrosis. Chest 1994; 105: 32-36.

223 Agarwal R, Aggarwal AN, Gupta D, et al. Aspergillus hypersensitivity and allergic bronchopulmonary aspergillosis in patients with bronchial asthma: systematic review and meta-analysis. Int J Tuberc Lung Dis 2009; 13: 936-944.

224 Maurya V, Gugnani HC, Sarma PU, et al. Sensitization to Aspergillus antigens and occurrence of allergic bronchopulmonary aspergillosis in patients with asthma. Chest 2005; 127: 1252-1259.

225 Schwartz HJ, Citron KM, Chester EH, et al. A comparison of the prevalence of sensitization to Aspergillus antigens among asthmatics in Cleveland and London. J Allergy Clin Immunol. 1978; 62: 9-14.

226 Tillie-Leblond I, Tonnel AB. Allergic bronchopulmonary aspergillosis. Allergy 2005; 60: 1004-1013.

227 Wang JL, Patterson R, Rosenberg $\mathrm{M}$, et al. Serum $\operatorname{IgE}$ and $\operatorname{IgG}$ antibody activity against Aspergillus fumigatus as a diagnostic aid in allergic bronchopulmonary aspergillosis. Am Rev Respir Dis 1978; 117: 917-927.

228 Cockrill BA, Hales CA. Allergic bronchopulmonary aspergillosis. Annu Rev Med 1999; 50: 303-316.

229 Knutsen AP, Slavin RG. In vitro T cell responses in patients with cystic fibrosis and allergic bronchopulmonary aspergillosis. J Lab Clin Med 1989; 113: 428-435.

230 Chauhan B, Santiago L, Kirschmann DA, et al. The association of HLA-DR alleles and T cell activation with allergic bronchopulmonary aspergillosis. J Immunol 1997; 159: 4072-4076.

231 Rosenberg M, Patterson R, Mintzer R, et al. Clinical and immunologic criteria for the diagnosis of allergic bronchopulmonary aspergillosis. Ann Intern Med 1977; 86: 405-414.

232 Mintzer RA, Rogers LF, Kruglik GD, et al. The spectrum of radiologic findings in allergic bronchopulmonary aspergillosis. Radiology 1978; 127: 301-307.

233 Greenberger PA, Patterson R. Diagnosis and management of allergic bronchopulmonary aspergillosis. Ann Allergy 1986; 56: 444-448.

234 Riscili BP, Wood KL. Noninvasive pulmonary aspergillus infections. Clin Chest Med 2009; 30: 315-335.

235 Bosken $\mathrm{CH}$, Myers JL, Greenberger PA, et al. Pathologic features of allergic bronchopulmonary aspergillosis. Am J Surg Pathol 1988; 12: 216-222.

236 Greenberger PA. Immunologic aspects of lung diseases and cystic fibrosis. JAMA 1997; 278: 1924-1930.

237 Patterson R, Greenberger PA, Radin RC, et al. Allergic bronchopulmonary aspergillosis: staging as an aid to management. Ann Intern Med 1982; 96: 286-291.

238 Patterson R, Greenberger PA, Halwig JM, et al. Allergic bronchopulmonary aspergillosis. Natural history and classification of early disease by serologic and roentgenographic studies. Arch Intern Med 1986; 146: 916-918.

239 Mikita CP, Mikita JA. Allergic bronchopulmonary aspergillosis. Allergy Asthma Proc 2006; 27: 82-84.

240 Hilton AM, Chatterjee SS. Bronchopulmonary aspergillosistreatment with beclomethasone dipropionate. Postgrad Med J 1975; 51: Suppl. 4, 98-103.

241 Seaton A, Seaton RA, Wightman AJ. Management of allergic bronchopulmonary aspergillosis without maintenance oral corticosteroids: a fifteen-year follow-up. QJM 1994; 87: 529-537.

242 Skov M, Main KM, Sillesen IB, et al. Iatrogenic adrenal insufficiency as a side-effect of combined treatment of itraconazole and budesonide. Eur Respir J 2002; 20: 127-133.

243 Hilliard T, Edwards S, Buchdahl R, et al. Voriconazole therapy in children with cystic fibrosis. J Cyst Fibros 2005; 4: 215-220.

244 van der Ent CK, Hoekstra H, Rijkers GT. Successful treatment of allergic bronchopulmonary aspergillosis with recombinant antiIgE antibody. Thorax 2007; 62: 276-277.

245 Lebecque P, Leonard A, De Boeck K, et al. Early referral to cystic fibrosis specialist centre impacts on respiratory outcome. J Cyst Fibros 2009; 8: 26-30.

246 Israel RH, Poe RH, Bomba PA, et al. The rapid development of an aspergilloma secondary to allergic bronchopulmonary aspergillosis. Am J Med Sci 1980; 280: 41-44.

247 McCarthy DS, Simon G, Hargreave FE. The radiological appearances in allergic broncho-pulmonary aspergillosis. Clin Radiol 1970; 21: 366-375.

248 Shah A. Allergic bronchopulmonary aspergillosis: an Indian perspective. Curr Opin Pulm Med 2007; 13: 72-80.

249 Ein ME, Wallace RJ Jr, Williams TW Jr. Allergic bronchopulmonary aspergillosis-like syndrome consequent to aspergilloma Am Rev Respir Dis 1979; 119: 811-820.

250 Shah A. Concurrent allergic bronchopulmonary aspergillosis and aspergilloma: is it a more severe form of the disease? Eur Respir Rev 2010; 19: 261-263.

251 Montani D, Zendah I, Achouh L, et al. Association of pulmonary aspergilloma and allergic bronchopulmonary aspergillosis. Eur Respir Rev 2010; 19: 349-351.

252 Riley DJ, Mackenzie JW, Uhlman WE, et al. Allergic bronchopulmonary aspergillosis: evidence of limited tissue invasion. Am Rev Respir Dis 1975; 111: 232-236.

253 Henderson AH. Allergic aspergillosis: review of 32 cases. Thorax 1968; 23: 501-512.

254 Ganassini A, Cazzadori A. Invasive pulmonary aspergillosis complicating allergic bronchopulmonary aspergillosis. Respir Med 1995; 89: 143-145.

255 Slavin RG, Bedrossian CW, Hutcheson PS, et al. A pathologic study of allergic bronchopulmonary aspergillosis. J Allergy Clin Immunol 1988; 81: 718-725.

256 Costabel U, Billmann P, Schaefer HE, et al. Invasive and granulomatous pulmonary aspergillosis with cerebral dissemination. Mycoses 1988; 31: Suppl. 1, 29-38.

257 Anderson CJ, Craig S, Bardana EJ Jr. Allergic bronchopulmonary aspergillosis and bilateral fungal balls terminating in disseminated aspergillosis. J Allergy Clin Immunol 1980; 65: 140-144.

258 Brown K, Rosenthal M, Bush A. Fatal invasive aspergillosis in an adolescent with cystic fibrosis. Pediatr Pulmonol 1999; 27: 130-133. 